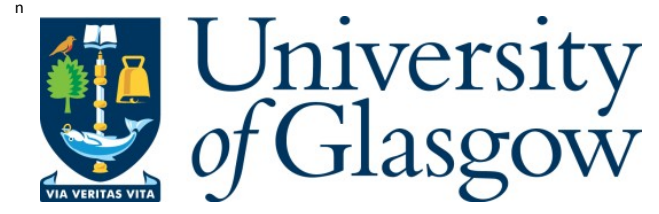

Peralagu, U . et al. (2015) (Invited) towards a vertical and damage free post-etch InGaA s fin profile: dry etch processing, sidewall damage assessment and mitigation options. ECS Transactions, 69(5), pp. 15-36.

There may be differences between this version and the published version. $Y$ ou are advised to consult the publisher's version if you wish to cite from it.

http://eprints.gla.ac.uk/111329/

Deposited on: 15 February 2016

Enlighten - R esearch publications by members of the U niversity of Glasgow http://eprints.gla.ac.uk 


\title{
Towards a Vertical and Damage Free Post-Etch InGaAs Fin Profile: Dry Etch Processing, Sidewall Damage Assessment and Mitigation Options
}

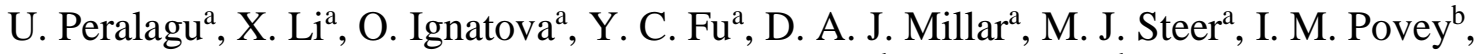

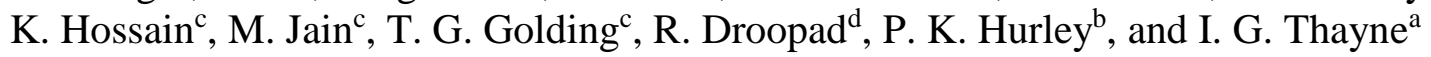 \\ ${ }^{\text {a }}$ School of Engineering, University of Glasgow, Glasgow, G12 8LT, United Kingdom \\ b Tyndall National Institute, University College Cork, Lee Maltings, Prospect Row, Cork, \\ Ireland \\ ${ }^{\mathrm{c}}$ Amethyst Research Incorporated, 123 Case Circle, Ardmore, Oklahoma 73401, USA \\ ${ }^{d}$ Ingram School of Engineering, Texas State University, San Marcos, Texas 78666, USA
}

\begin{abstract}
Based on current projections, III-Vs are expected to replace Si as the $\mathrm{n}$-channel solution in FinFETs at the $7 \mathrm{~nm}$ technology node. The realisation of III-V FinFETs entails top-down fabrication via dry etch techniques. Vertical fins in conjunction with high quality sidewall MOS interfaces are required for high-performance logic devices. This, however, is difficult to achieve with dry etching. Highly anisotropic etching required of vertical fins is concomitant with increased damage to the sidewalls, resulting in the quality of the sidewall MOS interface being compromised. In this work, we address this challenge in two stages by first undertaking a systematic investigation of dry etch processing for fin formation, with the aim of obtaining high resolution fins with vertical sidewalls and clean etch surfaces. In the second stage, dry etch process optimisation and post-etch sidewall passivation schemes are explored to mitigate the damage arising from anisotropic etching required for the realisation of vertical fins.
\end{abstract}

\section{Introduction}

For close to half a century, the success of the microelectronics industry has been driven by the continued dimensional scaling of the Si complementary-metal-oxide-semiconductor (CMOS) transistor, resulting in increased logic performance and device density at reduced manufacturing costs (1-3). However, conventional transistor scaling has encountered a serious impediment owing to the high power consumption of logic chips. The power problem is two-fold, the first being leakage currents due to short channel effects (SCE) which increases with further dimensional scaling (4). The other is the saturation of the supply voltage at around $1 \mathrm{~V}$. While a reduction in supply voltage would ease power consumption, this comes at the cost of switching speed (1-3). Novel device architectures and new channel materials, technologies referred to as being disruptive to mainstream CMOS (3), are therefore required for continued transistor scaling and supply voltage reduction to enable higher device densities, faster logic switching and energy efficiency. The first of these disruptive technologies has already been embraced at the $22 \mathrm{~nm}$ technology node $(4,5)$ with the planar metal-oxide-semiconductor field-effect-transistor (MOSFET) evolving to a FinFET, a three-dimensional device architecture which provides for improved electrostatic integrity $(3,4)$. While FinFETs are likely to feature in the logic 
roadmap for at least three generations, $\mathrm{Si}$ is only expected to feature for another two generations as the channel material. To counteract the performance loss of Si at the $7 \mathrm{~nm}$ technology node, novel channel materials - a second disruptive technology - would be required. These new materials must be able to deliver higher performance than $\mathrm{Si}$ at the same operating voltage (3).

III-V materials due to their high electron injection velocities appear highly promising as the n-channel solution for post-Si CMOS $(1,3)$. To make this a reality, substantial undertaking has gone into finding solutions for the technological challenges facing III-V MOSFETs $(1,6)$. InGaAs, in particular, has been the centre of extensive research effort with remarkable progress being made in the in the critical areas of gate stack $(7,8)$, parasitic resistance (9) and III-V/Si heterointegration (10). Recent impressive transistor performances (11-13) clearly demonstrate the extent to which III-V nMOSFET technology has matured. Despite these advances, further improvements are still needed to make III-Vs a viable CMOS option. The addition of a third dimension to the device architecture further requires dry etch processing, a top-down approach, for the fabrication of III-V fins.

Dry etching is a complex process, with its employment for pattern transfer being highly experimental and empirical. The choice of gas chemistry and the control of process parameters dictate the quality of the etch process in terms of selectivity, anisotropy, etch rate and uniformity (14-20). The utilization of dry etch processing, however, carries with it the inherent risk of damage to the semiconductor due to energetic ion bombardment and the presence of reactive ion species $(18,19,21)$. Etch-induced damage can manifest in various forms such as lattice defects (traps, vacancies and interstitials), lattice disordering (amorphisation) and surface roughness due to ion bombardment (19,21,22), surface contamination resulting from polymer deposition (21), dopant passivation by atomic hydrogen (21-23) and changes in surface stoichiometry due to preferential etching or layer intermixing (23-25). These effects can degrade the optical and electrical properties of the semiconductor, of detriment to the final device performance.

The development of dry etch processing for nanometre-scale fin definition in III-V transistors demands two key requirements to be met; realisation of vertical sidewalls and a high quality sidewall MOS interface. The improved electrostatic integrity of FinFETs featuring vertical sidewalls as opposed to tapered sidewalls aid in minimising SCE, thereby enhancing device performance (26). A smooth sidewall presenting with minimum etch damage enables a sidewall MOS interface of high quality to be obtained (27). However, satisfying both criteria is a challenging prospect. Highly anisotropic dry etching required for sidewall verticality is more damaging due to the physical nature of the process (21). Unlike Si, the induced damage cannot be cured by post etch annealing in III-Vs $(1,19)$.

In this work, we will first report on the dry etch processing systematically investigated for fin formation, with the aim of obtaining high resolution fins with vertical sidewalls and clean etch surfaces. The electrical damage arising from the most promising etch processes are evaluated from MOS capacitor (MOSCAP) measurements. Transmission electron microscopy (TEM) and atomic force microscopy (AFM) techniques are also used to determine structural and morphological properties. We will then present results on the mitigation of etch-induced sidewall damage. By means of dry etch process optimization we demonstrate a reduction in etch damage without compromising on sidewall verticality. Some examples of nanowires realized using this optimized process will also be shown. 
Two post-etch sidewall passivation schemes are further explored to alleviate damage. Details of the passivation schemes and the associated results are presented and discussed.

\section{Dry Etch Processing for Fin Formation and the Associated Damage}

\section{Fin Etching}

Hydrogen silsesquioxane (HSQ) was used as the etch mask for the transfer of fin patterns onto (100) oriented $\mathrm{In}_{0.53} \mathrm{Ga}_{0.47}$ As. Resist linewidths in the nanometric range were patterned by electron beam lithography using a Vistec VB6 UHR-EWF on HSQ limited to a thickness of $80 \mathrm{~nm}$. A HSQ etch mask with a range of linewidths between $10 \mathrm{~nm}$ and $100 \mathrm{~nm}$ was obtained with this process as shown in Fig. 1. This etch mask is used for all fin etch investigations presented in this paper.

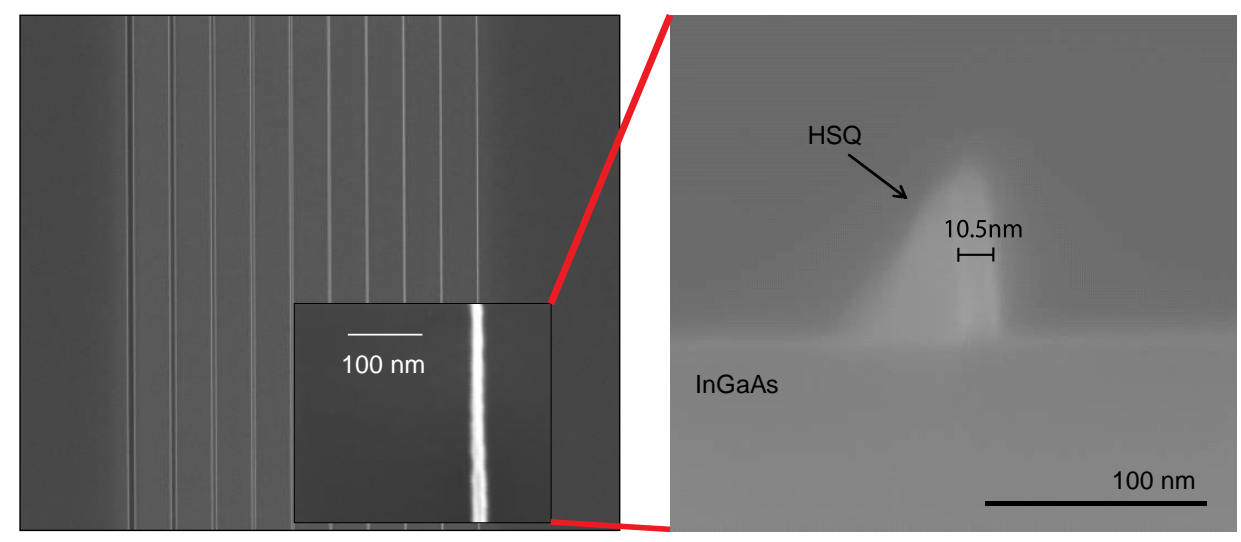

Figure 1. SEM of a HSQ etch mask, with linewidths in the range of $10 \mathrm{~nm}$ to $100 \mathrm{~nm}$, for fin pattern transfer.

Chlorine-based plasmas (e.g. $\mathrm{Cl}_{2}, \mathrm{BCl}_{3}, \mathrm{SiCl}_{4}$ ) and alkane/hydrogen-based plasmas (e.g. $\mathrm{CH}_{4} / \mathrm{H}_{2}$ ) are the two main gas chemistries used for etching III-V materials (14-18). Depending on the target III-V material to be etched and the specific application, various combinations of gas mixtures are derived from these basic chemistries with the inclusion of additive gases (e.g. Ar, $\left.\mathrm{N}_{2}, \mathrm{O}_{2}\right)$ to improve some aspect of the etch process $(19,20)$.

The initial fin etch experiments were carried out using a reactive ion etching (RIE) process based around a silicon tetrachloride $\left(\mathrm{SiCl}_{4}\right)$ gas chemistry. An Oxford Instruments PlasmaLab System 100 RIE tool was used for the investigation. Despite an expansive exploration of the parameter space including flow rate, power, chamber pressure, table temperatures and etch times, it proved impossible to find a process window that would yield high resolution $\operatorname{In}_{0.53} \mathrm{Ga}_{0.47}$ As fins with vertical sidewalls and clean etch surfaces. A truncated version of the experiments undertaken is presented here. In this study, four samples were etched at a constant gas flow rate of $25 \mathrm{sccm}$ while power and the corresponding self-bias, pressure, temperature and etch time were varied. The RIE parameters used for each sample are listed in Table I. The SEM micrographs relating to the etched samples are shown in Fig. 2. It is evident that all four etched samples have a rough surface morphology likely due to the In-enrichment of the surface owing to the low volatility of $\mathrm{InCl}(18,19)$. The sidewalls are also observed to be deteriorated by the rough 
morphology. This would significantly compromise the quality of the sidewall MOS interface.

TABLE I. Summary of RIE etch conditions, based around a $\mathrm{SiCl}_{4}$ chemistry, investigated for fin etching.

\begin{tabular}{ccccccc}
\hline Sample & $\begin{array}{c}\text { Gas Flow } \\
(\mathbf{s c c m})\end{array}$ & $\begin{array}{c}\text { Power } \\
(\mathbf{W})\end{array}$ & $\begin{array}{c}\text { Pressure } \\
(\mathbf{m T o r r})\end{array}$ & $\begin{array}{c}\text { Bias } \\
(\mathbf{V})\end{array}$ & $\begin{array}{c}\text { Temperature } \\
\left({ }^{\circ} \mathbf{C}\right)\end{array}$ & $\begin{array}{c}\text { Duration } \\
(\mathbf{s})\end{array}$ \\
\hline RIE-A & 25 & 50 & 8 & 182 & 37 & 240 \\
RIE-B & 25 & 150 & 8 & 375 & 39 & 120 \\
RIE-C & 25 & 150 & 4 & 400 & 39 & 120 \\
RIE-D & 25 & 150 & 4 & 388 & 100 & 120 \\
\hline
\end{tabular}
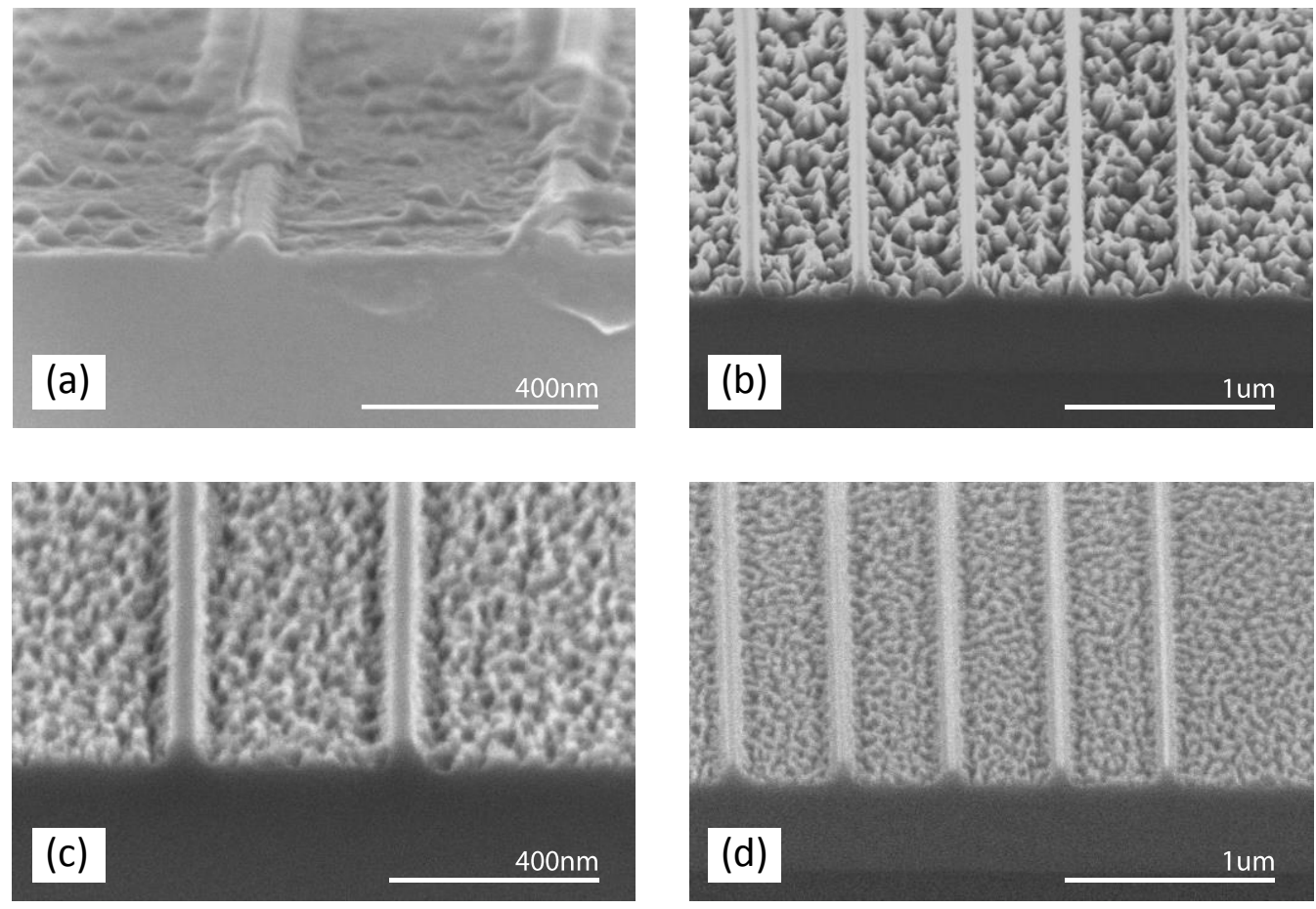

Figure 2. SEM of fins etched in $\mathrm{In}_{0.53} \mathrm{Ga}_{0.47} \mathrm{As}$ using a $\mathrm{SiCl}_{4}$ gas chemistry, for the RIE process conditions of (a) RIE-A, (b) RIE-B, (c) RIE-C and (d) RIE-D listed in Table I.

In the next set of fin etching experiments, a variety of chlorine-based chemistries were examined using an inductively coupled plasma (ICP) etch process. These experiments were conducted in an Oxford Instruments PlasmaPro System 100 ICP180 RIE tool. Based on a larger experimental matrix, the process conditions of four $\operatorname{In}_{0.53} \mathrm{Ga}_{0.47} \mathrm{As}$ samples etched in $\mathrm{Cl}_{2} / \mathrm{BCl}_{3}, \mathrm{Cl}_{2} / \mathrm{BCl}_{3} / \mathrm{Ar}$ and $\mathrm{Cl}_{2} / \mathrm{CH}_{4} / \mathrm{H}_{2}$ chemistries are summarized in Table II. The SEM micrographs of samples subject to the different etch recipes are shown in Fig. 3. It is notable that all etched samples present with a smooth surface morphology, a drastic improvement from the RIE process using a $\mathrm{SiCl}_{4}$ chemistry. Despite the smooth surfaces, it proved challenging to obtain vertical fins with $\mathrm{Cl}_{2} / \mathrm{BCl}_{3}$ and $\mathrm{Cl}_{2} / \mathrm{BCl}_{3} / \mathrm{Ar}$ etch processes. Sample ICP-A etched in $\mathrm{Cl}_{2} / \mathrm{BCl}_{3}$ yielded a $56.8^{\circ}$ sidewall-to substrate angle (Fig. 3(a)). For the same gas chemistry, a reduction in coil/platen power and pressure resulted in a lower sidewall angle of $49.8^{\circ}$ for sample ICP-B (Fig. 3(b)). There is no significant improvement in the slope of the sidewall $\left(55.7^{\circ}\right.$ ) for sample ICP-C etched using $\mathrm{Cl}_{2} / \mathrm{BCl}_{3} / \mathrm{Ar}$ (Fig. 3(c)), 
TABLE II. Summary of ICP etch conditions, for a variety of chlorine-based chemistries, investigated for fin etching.

\begin{tabular}{cccccccc}
\hline Sample & $\begin{array}{c}\text { Etch } \\
\text { Chemistry }\end{array}$ & $\begin{array}{c}\text { Flow } \\
(\mathbf{s c c m})\end{array}$ & $\begin{array}{c}\text { Coil/Platen } \\
\text { Power } \\
(\mathbf{W})\end{array}$ & $\begin{array}{c}\text { Pressure } \\
(\mathbf{m T o r r})\end{array}$ & $\begin{array}{c}\text { Bias } \\
(\mathbf{V})\end{array}$ & $\begin{array}{c}\text { Temperature } \\
\left({ }^{\circ} \mathbf{C}\right)\end{array}$ & $\begin{array}{c}\text { Duration } \\
(\mathbf{s})\end{array}$ \\
\hline $\mathrm{ICP}-\mathrm{A}$ & $\mathrm{Cl}_{2} / \mathrm{BCl}_{3}$ & $15 / 3$ & $800 / 30$ & 10 & 120 & 60 & 30 \\
$\mathrm{ICP}-\mathrm{B}$ & $\mathrm{Cl}_{2} / \mathrm{BCl}_{3}$ & $15 / 3$ & $400 / 15$ & 2 & 62 & 60 & 120 \\
$\mathrm{ICP}-\mathrm{C}$ & $\mathrm{Cl}_{2} / \mathrm{BCl}_{3} / \mathrm{Ar}$ & $12 / 3 / 6$ & $400 / 15$ & 2 & 62 & 60 & 120 \\
ICP-D & $\mathrm{Cl}_{2} / \mathrm{CH}_{4} / \mathrm{H}_{2}$ & $6 / 10 / 15$ & $500 / 75$ & 2 & 182 & 60 & 30 \\
\hline
\end{tabular}

despite the addition of Ar to the chemistry which should in essence provide for better anisotropic etching due to increased ion sputtering (28). The $\mathrm{Cl}_{2} / \mathrm{CH}_{4} / \mathrm{H}_{2}$ process, however, does show significantly more promise with the sidewall being within $3^{\circ}$ of vertical in the top half of the fin while the bottom half presents with a sidewall angle of $73^{\circ}$ (Fig. 3(d)). This improvement in verticality could be partly due to the enhanced sidewall passivation provided by $\mathrm{H}_{2}$ and $\mathrm{CH}_{4}$ in the chemistry $(20,29)$. On the other hand, physical sputtering is likely enhanced by the high platen power of the process resulting in more anisotropic etching $(18,21)$. The quality of etching was further analysed by AFM. Shown in Fig. 4 are the AFM scans of an unetched sample and samples blanket etched using the etch recipes
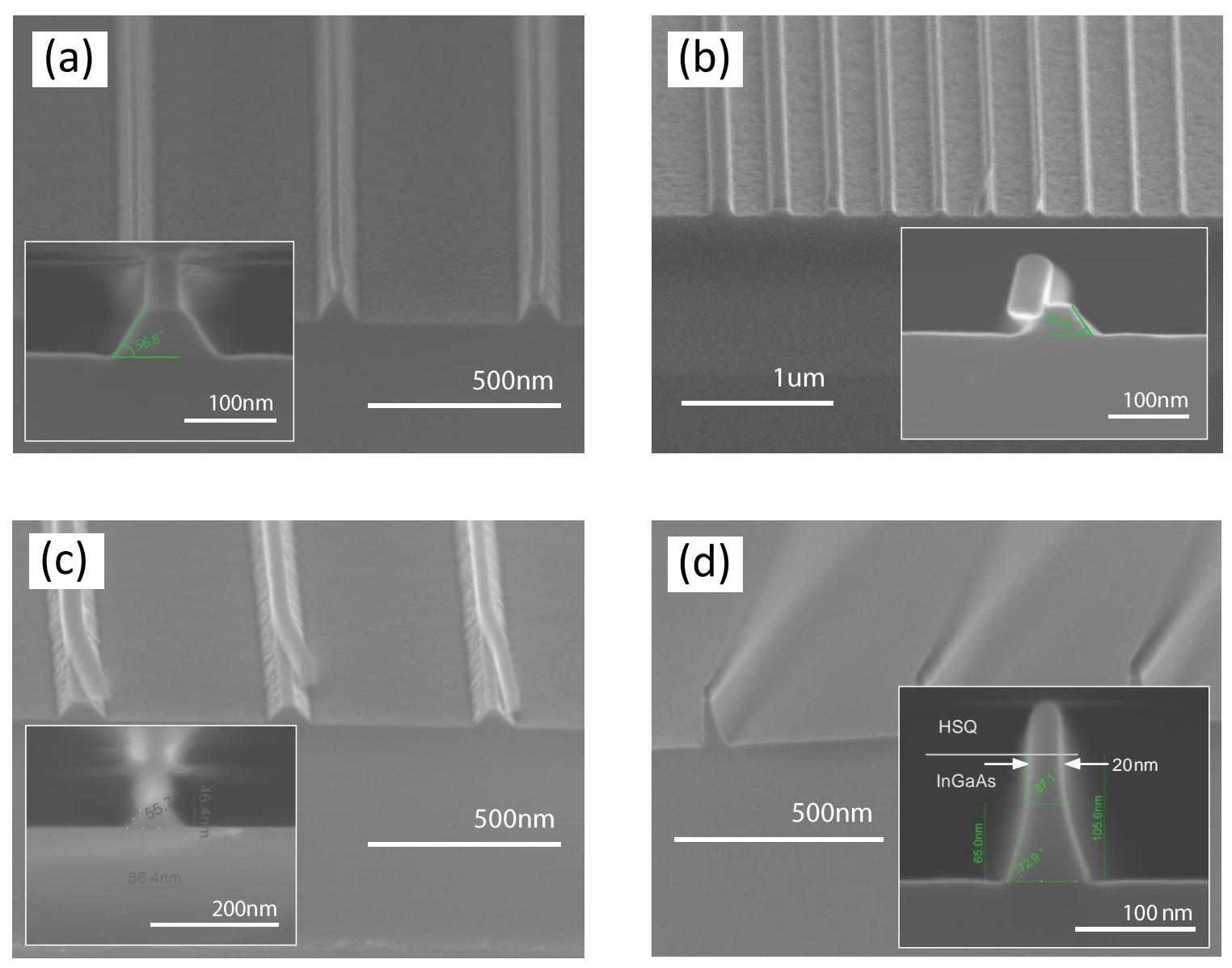

Figure 3. SEM of fins etched in $\operatorname{In}_{0.53} \mathrm{Ga}_{0.47} \mathrm{As}$ using a variety of chlorine-based chemistries, for the ICP process conditions of (a) ICP-A, (b) ICP-B, (c) ICP-C and (d) ICP-D listed in Table II. 
detailed in Table II, with measured roughness indicated. For the $\mathrm{Cl}_{2} / \mathrm{BCl}_{3}$ processes, the surface roughness increased with longer etch times. Introducing $\mathrm{Ar}$ to the $\mathrm{Cl}_{2} / \mathrm{BCl}_{3}$ does not result in additional surface roughness. The $\mathrm{Cl}_{2} / \mathrm{CH}_{4} / \mathrm{H}_{2}$ process had comparable roughness to the $\mathrm{Cl}_{2} / \mathrm{BCl}_{3}$ process for a given etch time. The roughness of all etched samples are deemed to be within the range of device quality etching.

(a)

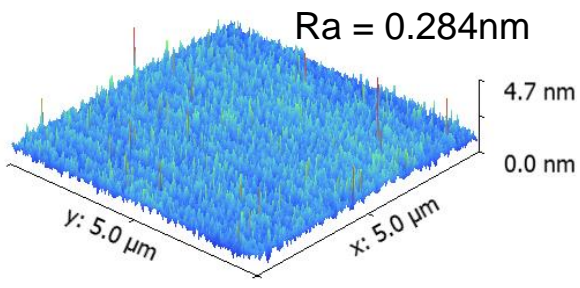

(b)
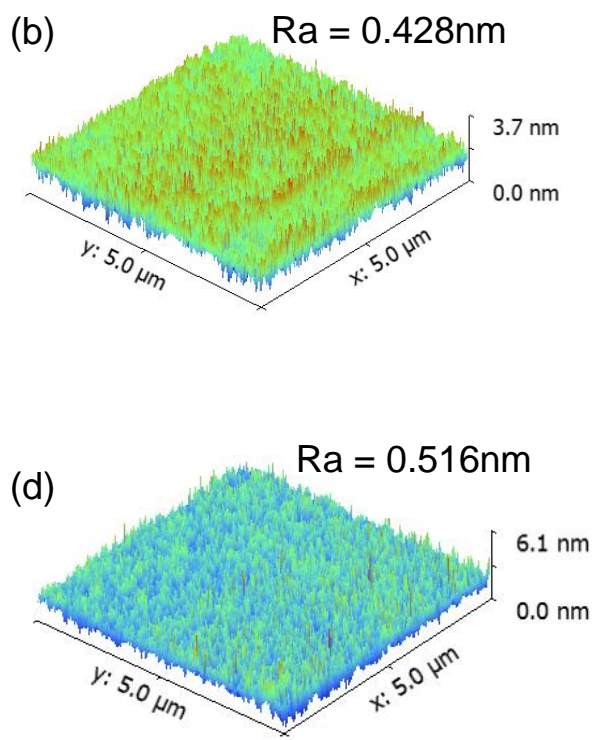

(c)

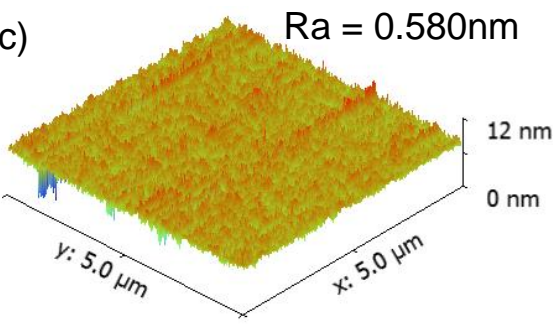

(e)

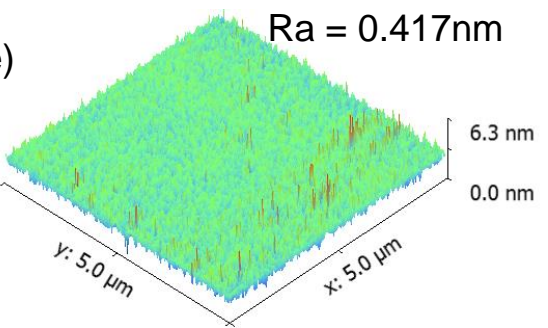

Figure 4. $5 \times 5 \mu \mathrm{m}$ AFM scans of (a) unetched (control) sample and samples blanket etched using the ICP etch conditions of (b) ICP-A, (c) ICP-B, (d) ICP-C and (e) ICP-D listed in Table II.

An etch process for the realisation of vertical $\operatorname{In}_{0.53} \mathrm{Ga}_{0.47} \mathrm{As}$ fins with a high aspect ratio was also explored using the $\mathrm{Cl}_{2} / \mathrm{CH}_{4} / \mathrm{H}_{2}$ chemistry. A large matrix of etch experiments was carried out with variations in RF platen power (0-250W), ICP coil power (100-2000W), chamber pressure $(1-10 \mathrm{mTorr})$, temperature $\left(0-60^{\circ} \mathrm{C}\right)$ and gas flow rates. This led to the realisation of a highly vertical $10 \mathrm{~nm} \mathrm{In}_{0.53} \mathrm{Ga}_{0.47} \mathrm{As}$ fin with $16: 1$ aspect ratio as shown in Fig. 5(a), perhaps the highest aspect ratio, smallest critical dimension fins that been demonstrated to date in $\mathrm{In}_{0.53} \mathrm{Ga} 0.47 \mathrm{As}$. The details of this fin etch process are $\mathrm{Cl}_{2} / \mathrm{CH}_{4} / \mathrm{H}_{2}$ : $6 / 10 / 15 \mathrm{sccm}$, coil/platen powers of $1000 / 75 \mathrm{~W}, 2 \mathrm{mTorr}, 198 \mathrm{~V}, 60^{\circ} \mathrm{C}, 45 \mathrm{~s}$. AFM was also used to analyse the etched surface as shown in Fig. 5(b). The measured roughness of $0.456 \mathrm{~nm}$ is indicative of device quality etching. 

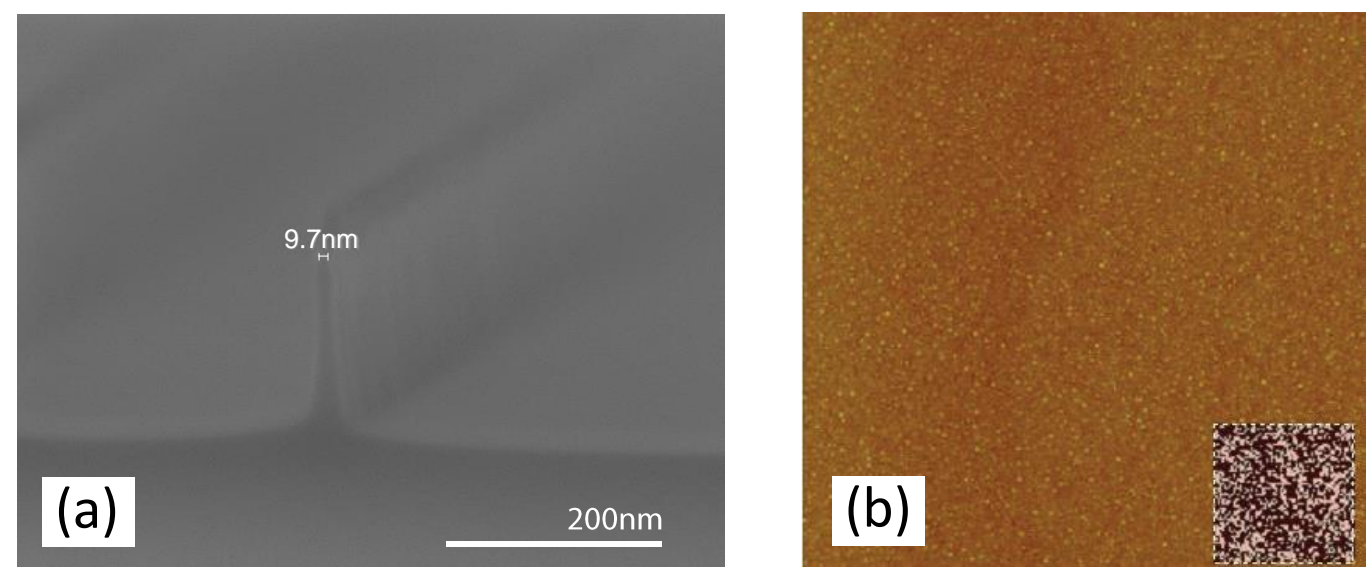

Figure 5. (a) SEM of a vertical $10 \mathrm{~nm} \operatorname{In}_{0.53} \mathrm{Ga}_{0.47} \mathrm{As}$ fin with a high aspect ratio of $16: 1$ realised using a $\mathrm{Cl}_{2} / \mathrm{CH}_{4} / \mathrm{H}_{2}$ etch process and (b) $8 \times 8 \mu \mathrm{m}$ and $2 \times 2 \mu \mathrm{m}$ (inset) AFM scans of the etched $\mathrm{In}_{0.53} \mathrm{Ga}_{0.47} \mathrm{As}$ surface.

\section{Sidewall Damage Assessment}

A wide variety of a techniques such as x-ray photoelectron spectroscopy, secondary ion mass spectroscopy, Auger electron microscopy, photoluminescence, Hall measurements, Schottky diode measurements, conductivity measurements of quantum wires, etc. (14,16-19,21-25,30-33) have been used to yield structural, chemical and electrical information relating to etch-induced damage. Our concern here is the extent of electrical damage to the dielectric/sidewall interface. In MOS technology, the electrical properties at the dielectric/semiconductor interface are routinely studied from capacitancevoltage (C-V) characteristics derived from MOSCAPs (6-8). On the basis of this, the impact of the etch processes on the electrical properties of the sidewall MOS interface is assessed from MOSCAP measurements in this work.

Here, the aim is to correlate the electrical damage to the ICP based fin etch processes detailed in Table II. As a first step, samples of (100) oriented $\operatorname{In}_{0.53} \mathrm{Ga}_{0.47} \mathrm{As}, 1 \mu \mathrm{m}$ thick, $\mathrm{n}$ doped $2 \times 10^{16} \mathrm{~cm}^{-3}$ grown on an $\mathrm{n}+$ substrate by molecular beam epitaxy (MBE) are subjected to the etch processes. These samples are not patterned, they are simply blanket etched using the fin etch conditions. Although this does not fully mimic the processes that FinFET sidewalls will experience, it will give an initial indication of the likely impact of the etch conditions on the $\operatorname{In}_{0.53} \mathrm{Ga}_{0.47} \mathrm{As}$ surface, via the electrical characteristics of MOSCAPs which are subsequently formed on the etched surface using the process flow shown in Fig. 6. The samples are treated in $10 \%\left(\mathrm{NH}_{4}\right)_{2} \mathrm{~S}$ for $20 \mathrm{~min}$ at room temperature immediately prior to atomic layer deposition (ALD) of 8nm-thick (nominal) $\mathrm{Al}_{2} \mathrm{O}_{3}$ film.

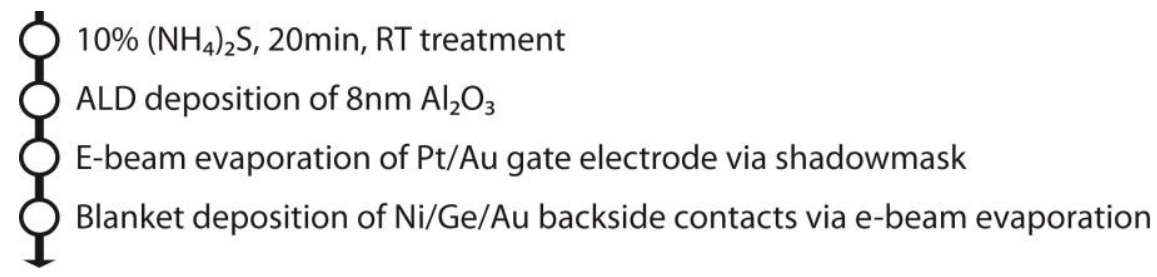

Figure 6. Process flow for fabrication of MOSCAP on blanket etched InGaAs. 
The gate electrode was defined via a shadow mask through which a Pt/Au contact was electron-beam (e-beam) evaporated. A backside contact was formed by blanket e-beam deposition of Ni/Ge/Au on the back of the samples. A MOSCAP was also fabricated on an unetched sample to serve as a control in the study.

Shown in Fig. 7 are the room temperature multi-frequency $(1 \mathrm{kHz}$ to $1 \mathrm{MHz}) \mathrm{C}-\mathrm{V}$ characteristics of the unetched (control) sample and samples subject to the ICP etch processes listed in Table II. The key electrical metrics derived from the $\mathrm{C}-\mathrm{V}$ data of Fig. 7,
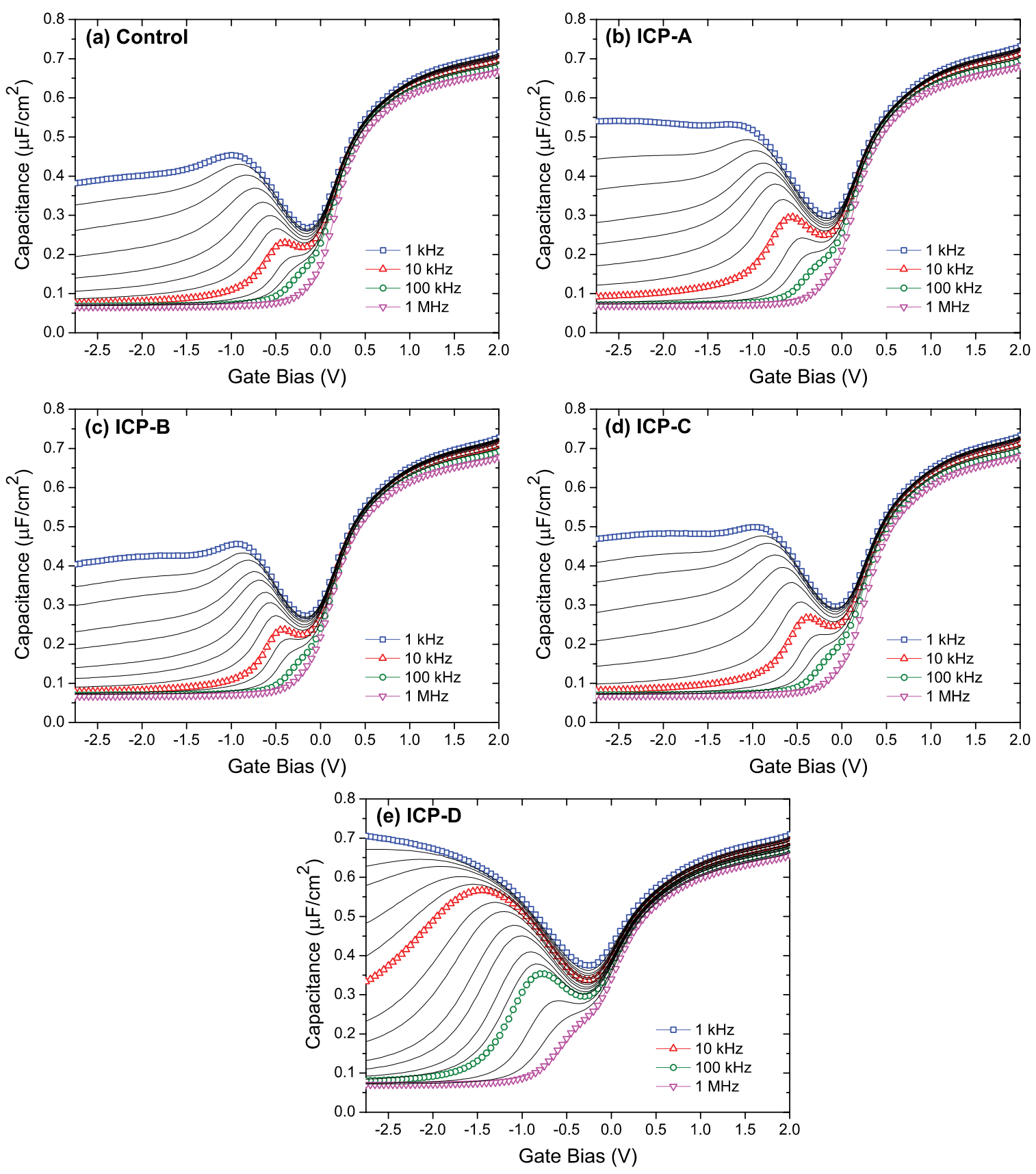

Figure 7. Multi-frequency, room temperature $\mathrm{C}-\mathrm{V}$ characteristics of $\mathrm{Au} / \mathrm{Pt} / \mathrm{Al}_{2} \mathrm{O}_{3} / \mathrm{n}$ $\mathrm{In}_{0.53} \mathrm{Ga}_{0.47}$ As MOSCAPs with the InGaAs sample (a) unetched (control) and etched for the ICP conditions of (b) ICP-A , (c) ICP-B, (d) ICP-C and (e) ICP-D listed in Table II. 
specifically the frequency dispersion in accumulation $\left(\Delta \mathrm{C}_{\mathrm{acc}}\right)$, stretch-out of the $\mathrm{C}-\mathrm{V}$ curve $(\mathrm{dC} / \mathrm{dV})$, frequency dispersion in depletion $(\Delta \mathrm{mV})$ and hysteresis at $1 \mathrm{MHz}$ are summarised in Table III. The definitions used for the extraction of these metrics can be found in Ref. 34. Percentages, displayed in the table, are used to compare and quantify the difference in metrics between an etched sample and a control sample. It is also worth pointing out that a decrease in $\mathrm{dC} / \mathrm{dV}$ is taken to mean an increase in the stretch-out.

TABLE III. Summary of metrics derived from the C-V responses of an unetched (control) sample and samples etched under a variety of chlorine-based chemistries for the ICP conditions given in Table II.

\begin{tabular}{|c|c|c|c|c|}
\hline MOSCAP Sample & $\begin{array}{l}\Delta C_{\text {acc }} \\
(\% / \text { dec })\end{array}$ & $\begin{array}{c}\mathrm{dC} / \mathrm{dV} \times \mathbf{1 0}^{-7} \\
\left(\mathrm{~F} / \mathrm{cm}^{2} . \mathrm{V}\right)\end{array}$ & $\begin{array}{l}\Delta \mathbf{m V} \\
(\mathbf{m V})\end{array}$ & $\begin{array}{c}\text { Hysteresis } \\
(\mathrm{mV})\end{array}$ \\
\hline Control & 2.17 & 9.15 & 100.7 & 126.0 \\
\hline ICP-A & $2.28(+5.1 \%)$ & $8.38(-8.4 \%)$ & $105.2(+4.5 \%)$ & $117.4(-6.8 \%)$ \\
\hline ICP-B & $2.29(+5.5 \%)$ & $8.27(-9.6 \%)$ & $70.7(-29.8 \%)$ & $84.8(-32.7 \%)$ \\
\hline ICP-C & $2.33(+7.4 \%)$ & $8.27(-9.6 \%)$ & $139.2(+38.2 \%)$ & $105.8(-16.0 \%)$ \\
\hline ICP-D & $2.48(+14.3 \%)$ & $5.31(-42.0 \%)$ & $169.1(+67.9 \%)$ & $190.3(+51.0 \%)$ \\
\hline
\end{tabular}

Samples ICP-A, ICP-B and ICP-C, etched in $\mathrm{Cl}_{2} / \mathrm{BCl}_{3}$ based chemistries, presented with a $5-7.5 \%$ increase in $\Delta \mathrm{C}_{\mathrm{acc}}$ and a $8-10 \%$ increase in stretch-out. While $\Delta \mathrm{mV}$ of samples ICP-A and ICP-C are increased from that of the control sample, ICP-B in fact shows a reduction. The hysteresis of all samples etched in $\mathrm{Cl}_{2} / \mathrm{BCl}_{3}$ based process is smaller than that of the control sample. In contrast, the metrics of sample ICP-D subject to the $\mathrm{Cl}_{2} / \mathrm{CH}_{4} / \mathrm{H}_{2}$ etch process, which produced the best fin profile among all the etch recipes, are found to be significantly degraded. It is notable that amongst the etched samples, ICP$\mathrm{D}$ demonstrates the largest degradation across all metrics.

In the depletion region, the $\mathrm{C}-\mathrm{V}$ responses are comparable between the control sample and samples etched in $\mathrm{Cl}_{2} / \mathrm{BCl}_{3}$ chemistry, including $\mathrm{Ar}$ (Figs. 7(a)-(d)). It is observed that the $\mathrm{C}-\mathrm{V}$ responses go through a peak in the gate bias range of $0 \mathrm{~V}$ to $-1.5 \mathrm{~V}$. Such a peak response is a characteristic signature of interface defects $(7,8,35)$. While peak responses are also observed in the $\mathrm{C}-\mathrm{V}$ curves of the sample etched in the $\mathrm{Cl}_{2} / \mathrm{CH}_{4} / \mathrm{H}_{2}$ chemistry, the peaks are noticeably broader and higher in magnitude (Fig. 7(e)) which suggests an increase in interface defect density $\left(\mathrm{D}_{\mathrm{it}}\right)(35)$. The deterioration of the interface properties of the sample etched in $\mathrm{Cl}_{2} / \mathrm{CH}_{4} / \mathrm{H}_{2}$ is also noted from the significant peak on the $1 \mathrm{MHz}$ response. A similar feature is not present in the $\mathrm{C}-\mathrm{V}$ response of the control sample or the other etched samples. Equivalent parallel conductance $\left(\mathrm{G}_{\mathrm{p}} / \omega\right)$ can be used to provide an indication of the relative differences in defect densities between the etched samples and the control sample since there is direct correlation between $\mathrm{G}_{\mathrm{p}} / \omega$ and $\mathrm{D}_{\mathrm{it}}(35)$. In Fig. 8, plots of $\mathrm{G}_{\mathrm{p}} / \omega$ as a function of gate bias at a constant frequency of $1 \mathrm{MHz}$ and $100 \mathrm{kHz}$ are shown. The peak magnitudes of $\mathrm{G}_{\mathrm{p}} / \omega$ is increased by a factor of 1.5-2 for samples etched in $\mathrm{Cl}_{2} / \mathrm{BCl}_{3}$ based chemistries in comparison to the control sample. On the other hand, the conductance peak of the sample etched in $\mathrm{Cl}_{2} / \mathrm{CH}_{4} / \mathrm{H}_{2}$ is a factor of $6.5-8.5$ greater than the control sample. 

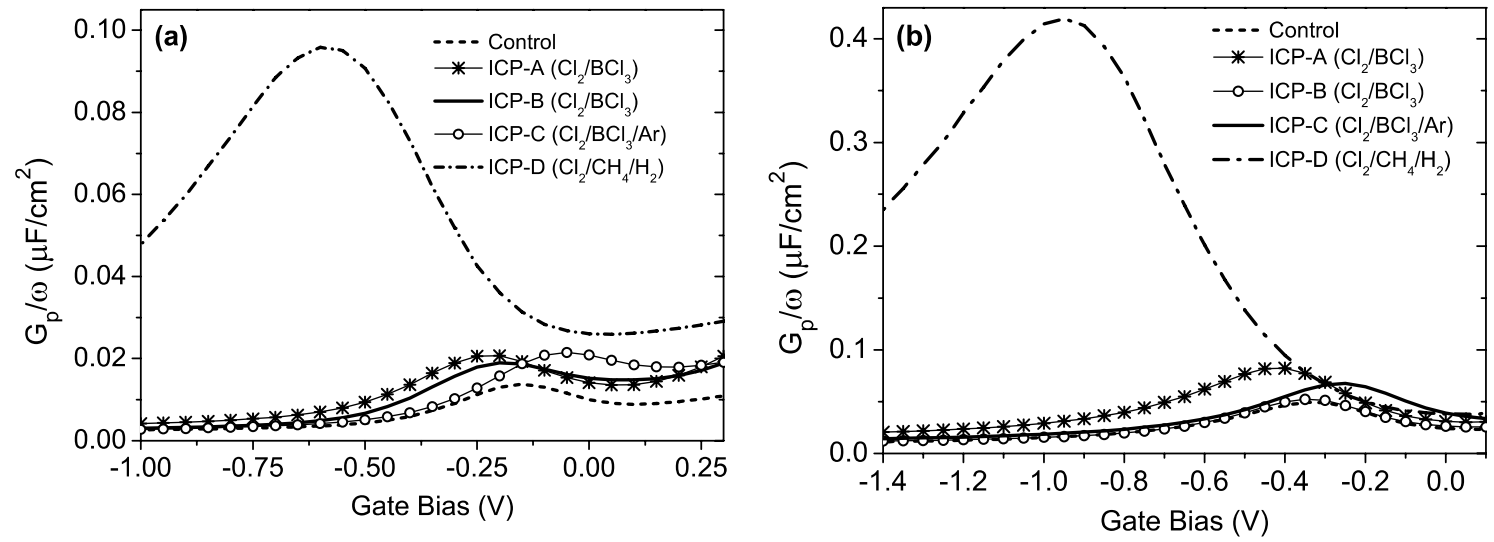

Figure 8. $\mathrm{G}_{\mathrm{p}} / \omega$ versus $\mathrm{V}_{\mathrm{g}}$ of $\mathrm{Au} / \mathrm{Pt} / \mathrm{Al}_{2} \mathrm{O}_{3} / \mathrm{n}-\mathrm{In}_{0.53} \mathrm{Ga}_{0.47} \mathrm{As}$ MOSCAPs, with the InGaAs sample unetched (control) and etched using the ICP processes listed in Table II, at a constant frequency of (a) $1 \mathrm{MHz}$ and (b) $100 \mathrm{kHz}$.

Based on the aforementioned analysis it is clear the $\mathrm{Cl}_{2} / \mathrm{CH}_{4} / \mathrm{H}_{2}$ etch process induces substantial damage to the $\operatorname{In}_{0.53} \mathrm{Ga}_{0.47} \mathrm{As}$ surface, despite the fact the surface roughness obtained with this process is smaller than that of the $\mathrm{Cl}_{2} / \mathrm{BCl}_{3}$ based etch processes. It is possible that methane and hydrogen present in the chemistry could be causing polymers and/or carbon based contaminants to be deposited on the $\operatorname{In}_{0.53} \mathrm{Ga}_{0.47}$ As surface, resulting in the quality of the interface to be degraded. To elucidate such effects, TEM analysis was undertaken. Shown in Fig. 9 are the cross-sectional TEM micrographs obtained from each of the etched samples and the control sample following high-k dielectric and metal gate deposition. These images confirm the thickness of the $\mathrm{Al}_{2} \mathrm{O}_{3}$, and correlate well with the roughness measurements on each sample. From the TEM images, it is clear there is a sharp transition from the $\mathrm{In}_{0.53} \mathrm{Ga}_{0.47} \mathrm{As}$ to the $\mathrm{Al}_{2} \mathrm{O}_{3}$ film with no obvious interlayer. Particularly, for the $\mathrm{Cl}_{2} / \mathrm{CH}_{4} / \mathrm{H}_{2}$, there is no evidence of polymer deposition or the presence of carbon on the $\mathrm{In}_{0.53} \mathrm{Ga}_{0.47} \mathrm{As}$ surface, to impact the electrical performance of the MOSCAPs. The damage, therefore, is likely arising from the physical nature of the $\mathrm{Cl}_{2} / \mathrm{CH}_{4} / \mathrm{H}_{2}$ etch process. The high anisotropy required for the realisation of near vertical fins with this etch process is primarily provided by ion sputtering. The enhanced ion bombardment, however, also induces more damage $(18,21)$. The degree of damage is directly proportional to the ion energy and inversely proportional to the ion mass (18). Looking back at Table II, the platen power used with the $\mathrm{Cl}_{2} / \mathrm{CH}_{4} / \mathrm{H}_{2}$ etch process is noticeably higher compared to all the other etch processes. The etch-induced damage can therefore be minimised by lowering the platen power, which in turn reduces the ion energy. 


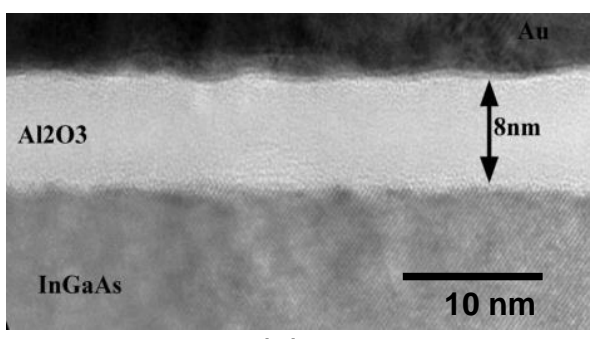

(a)

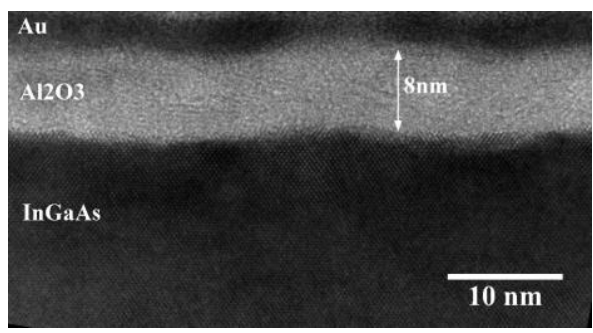

(c)

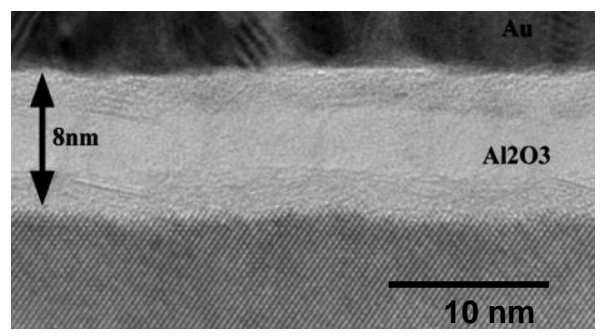

(b)

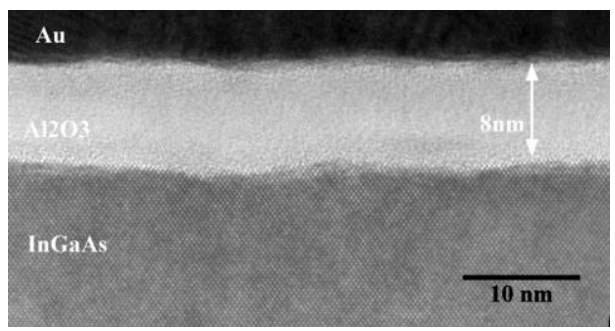

(d)

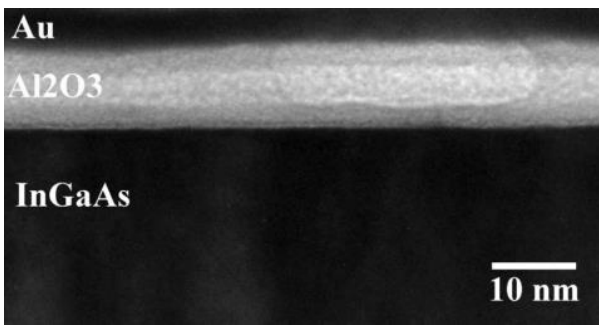

(e)

Figure 9. Cross-sectional TEM of $\operatorname{In}_{0.53} \mathrm{Ga}_{0.47} \mathrm{As}$ samples subject to (a) no etching and blanket etched using the ICP conditions of (b) ICP-A, (c) ICP-B, (d) ICP-C and (e) ICP-D listed in Table II, prior to high-k and metal gate deposition.

\section{Mitigation of Etch-induced Sidewall Damage}

\section{Dry Etch Process Optimization}

As previously shown, the realisation of fins with near- $90^{\circ}$ sidewall verticality based on a $\mathrm{Cl}_{2} / \mathrm{CH}_{4} / \mathrm{H}_{2}$ etch process comes at the cost of significant etch-induced damage. It was highlighted that the high platen power of $75 \mathrm{~W}$ used in the process is likely responsible for this. In an effort to minimise the damage an ICP etch process based around a $\mathrm{Cl}_{2} / \mathrm{CH}_{4} / \mathrm{H}_{2} / \mathrm{O}_{2}$ chemistry is explored. The addition of $\mathrm{O}_{2}$ to the etch chemistry allows for the platen power to be lowered, which should help with reducing the etch-induced damage without compromising the fin sidewall profile.

Fins were etched in (100) oriented $\operatorname{In}_{0.53} \mathrm{Ga}_{0.47} \mathrm{As}(30 \mathrm{~nm}) / \mathrm{In}_{0.52} \mathrm{Al}_{0.48} \mathrm{As}$ samples using the HSQ etch mask shown in Fig. 1, to obtain fin heights in the range of 40-50nm. Two fin etch recipes were investigated, with the only difference being the platen temperature. The process details are $\mathrm{Cl}_{2} / \mathrm{CH}_{4} / \mathrm{H}_{2} / \mathrm{O}_{2}: 6 / 10 / 15 / 0.5 \mathrm{sccm}$, coil/platen powers of 200/25W, 2mTorr, 113V, 5min. Shown in Fig. 10 are the SEM micrographs of fins etched using the aforementioned process conditions at temperatures of $60^{\circ} \mathrm{C}$ and $120^{\circ} \mathrm{C}$. Highly vertical fin profiles are realised with both etch recipes. The fins etched at the higher 
temperature though show a more vertical sidewall profile, which closely resembles that of the fins etched in the $\mathrm{Cl}_{2} / \mathrm{CH}_{4} / \mathrm{H}_{2}$ chemistry (Fig. 3(d)).
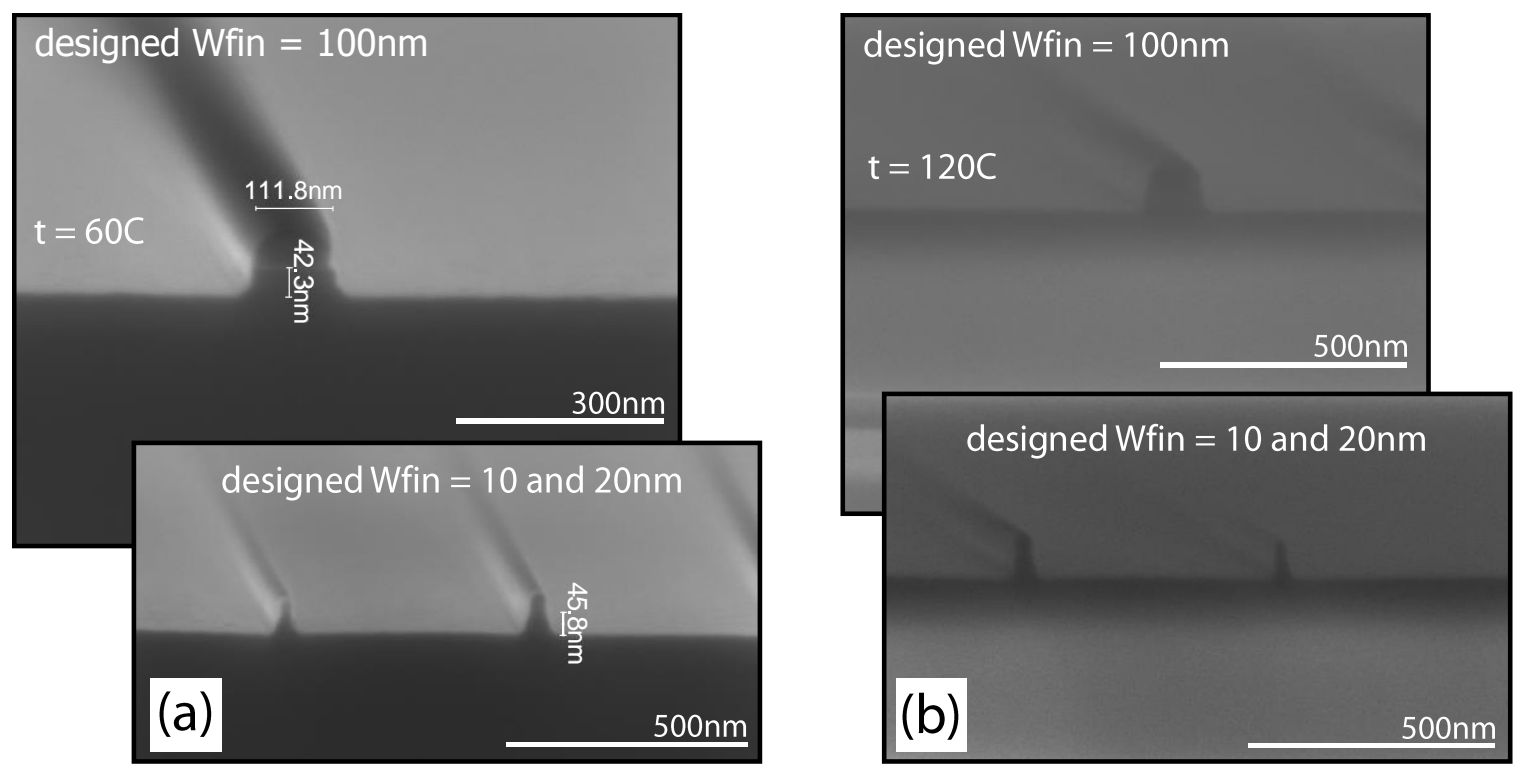

Figure 10. SEM of fins etched in $\operatorname{In}_{0.53} \mathrm{Ga}_{0.47} \mathrm{As}(30 \mathrm{~nm}) / \mathrm{In}_{0.52} \mathrm{Al}_{0.48} \mathrm{As}$ using a $\mathrm{Cl}_{2} / \mathrm{CH}_{4} / \mathrm{H}_{2} / \mathrm{O}_{2}$ chemistry at temperatures of (a) $60^{\circ} \mathrm{C}$ and (b) $120^{\circ} \mathrm{C}$ for the process conditions of $\mathrm{Cl}_{2} / \mathrm{CH}_{4} / \mathrm{H}_{2} / \mathrm{O}_{2}: 6 / 10 / 15 / 0.5 \mathrm{sccm}$, coil/platen powers : 200/25W, $2 \mathrm{mT}, 113 \mathrm{~V}$, $5 \mathrm{~min}$.

To assess the damage associated with the $\mathrm{Cl}_{2} / \mathrm{CH}_{4} / \mathrm{H}_{2} / \mathrm{O}_{2}$ etch processes, MOSCAPs were fabricated on samples of (100) oriented $\mathrm{In}_{0.53} \mathrm{Ga}_{0.47} \mathrm{As}, 1 \mu \mathrm{m}$ thick, n-doped $4 \times 10^{17}$ $\mathrm{cm}^{-3}$ using the process flow illustrated in Fig. 6. A MOSCAP fabricated on an unetched sample served as a control in the study. In Figs. 11(a)-(c) the room temperature multifrequency $(1 \mathrm{kHz}$ to $1 \mathrm{MHz}) \mathrm{C}-\mathrm{V}$ characteristics of the control sample and samples etched at the temperatures of $60^{\circ} \mathrm{C}$ and $120^{\circ} \mathrm{C}$, denoted as $\mathrm{A}$ and $\mathrm{B}$, are displayed. Etch-induced damage is observed from the peak responses being broader and of higher magnitude in the etched samples. It is further noted the fin etch process performed at the lower temperature of $60^{\circ} \mathrm{C}$ gives rise to more damage as the peaks are observed to be broader and larger in magnitude compared to sample A. From the plot of $G_{p} / \omega$ versus $V_{g}$ (Fig. 11(d)), conductance peaks of samples $\mathrm{A}$ and $\mathrm{B}$ are found to be $4.5 \mathrm{x}$ and $2.75 \mathrm{x}$ larger in relation to the control sample as opposed to the larger factor of 8.5 reported earlier for the $\mathrm{Cl}_{2} / \mathrm{CH}_{4} / \mathrm{H}_{2}$ chemistry (Fig. 8(b)).

Table IV summarises the electrical metrics of the control and etched samples determined from their respective $\mathrm{C}-\mathrm{V}$ characteristics. Frequency dispersion in accumulation and depletion along with stretch-out are observed to be less degraded for sample B. While both the etched samples demonstrate a reduction in hysteresis, a larger improvement is noted for sample $\mathrm{B}$. These observations in conjunction with the aforementioned $\mathrm{G}_{\mathrm{p}} / \omega$ analysis suggest the higher temperature etch process renders less damage to the sidewall. Moreover, in contrast to the $\mathrm{Cl}_{2} / \mathrm{CH}_{4} / \mathrm{H}_{2}$ etch process there is a marked improvement in the metrics of samples subject to the $\mathrm{Cl}_{2} / \mathrm{CH}_{4} / \mathrm{H}_{2} / \mathrm{O}_{2}$ etch process 
with respect to the control sample. This indicates the lower platen power arising from the addition of $\mathrm{O}_{2}$ to the $\mathrm{Cl}_{2} / \mathrm{CH}_{4} / \mathrm{H}_{2}$ chemistry results in a substantial reduction of etchinduced damage.
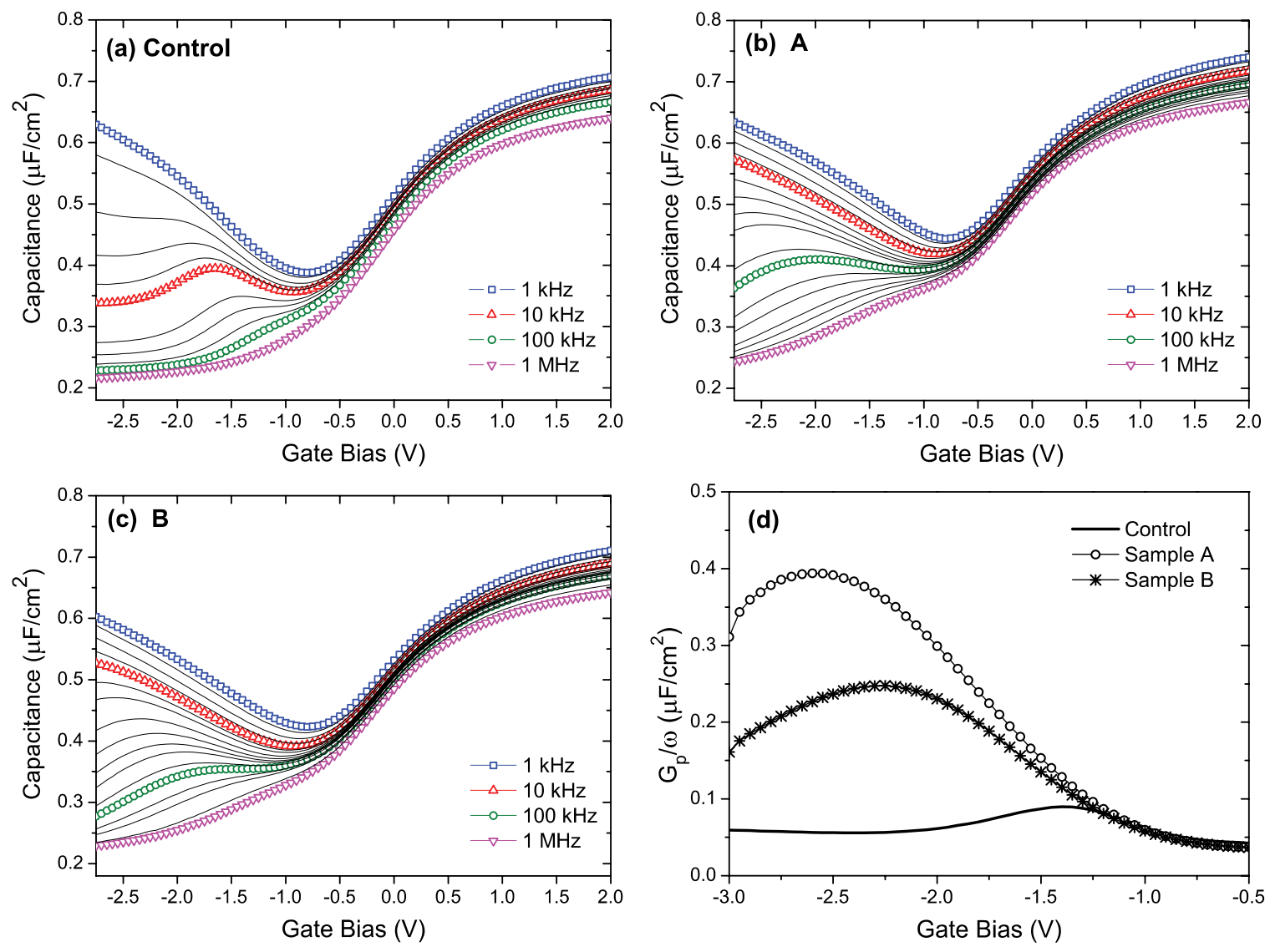

Figure 11. Multi-frequency, room temperature $\mathrm{C}-\mathrm{V}$ characteristics of $\mathrm{Au} / \mathrm{Pt} / \mathrm{Al}_{2} \mathrm{O}_{3} / \mathrm{n}$ $\mathrm{In}_{0.53} \mathrm{Ga}_{0.47} \mathrm{As}$ MOSCAPs with the InGaAs sample (a) unetched (control) and etched in $\mathrm{Cl}_{2} / \mathrm{CH}_{4} / \mathrm{H}_{2} / \mathrm{O}_{2}$ chemistry at the temperatures of (b) $60^{\circ} \mathrm{C}$ and (c) $120^{\circ} \mathrm{C}$, and (d) the resulting $\mathrm{G}_{\mathrm{p}} / \omega$ versus $\mathrm{V}_{\mathrm{g}}$ at a constant frequency of $100 \mathrm{kHz}$.

TABLE IV. Summary of metrics derived from the C-V responses of an unetched (control) sample and samples $A$ and $B$ etched in a $\mathrm{Cl}_{2} / \mathrm{CH}_{4} / \mathrm{H}_{2} / \mathrm{O}_{2}$ chemistry at temperatures of $60^{\circ} \mathrm{C}$ and $120^{\circ} \mathrm{C}$.

\begin{tabular}{ccccc}
\hline Sample & $\begin{array}{c}\Delta \mathbf{C}_{\text {acc }} \\
(\boldsymbol{\%} / \mathbf{d e c})\end{array}$ & $\begin{array}{c}\mathbf{d C / d V} \times \mathbf{~ 1 0}^{-7} \\
\left(\mathbf{F} / \mathbf{c m}^{2} \mathbf{. V}\right)\end{array}$ & $\begin{array}{c}\Delta \mathbf{m V} \\
(\mathbf{m V})\end{array}$ & $\begin{array}{c}\text { Hysteresis } \\
(\mathbf{m V})\end{array}$ \\
\hline Control & 2.18 & 2.21 & 200.2 & 450 \\
A & $2.59(+19.0 \%)$ & $1.95(-11.8 \%)$ & $208.3(+4.0 \%)$ & $383(-14.9 \%)$ \\
B & $2.44(+10.6 \%)$ & $2.14(-3.2 \%)$ & $206.7(+3.2 \%)$ & $351(-22.0 \%)$ \\
\hline
\end{tabular}


The $\mathrm{Cl}_{2} / \mathrm{CH}_{4} / \mathrm{H}_{2} / \mathrm{O}_{2}$ etch chemistry was also explored for nanowire etching on samples of (100) oriented $\mathrm{In}_{0.53} \mathrm{Ga}_{0.47} \mathrm{As}$, using HSQ as an etch mask. As shown in Fig. $12 \mathrm{HSQ}$, limited to a thickness of $40 \mathrm{~nm}$, was patterned using high-resolution electron beam lithography to produce an array of nano pillars, each with a diameter of $33 \mathrm{~nm}$.

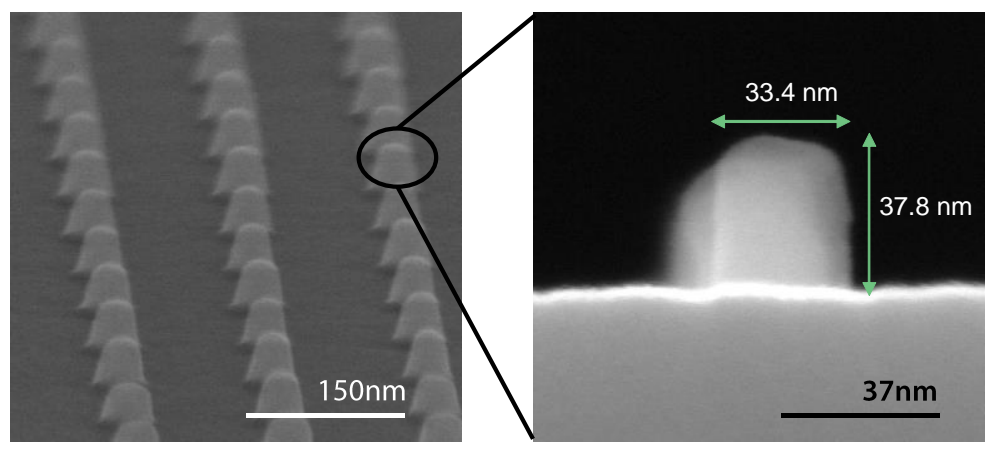

Figure 12. SEM of a HSQ etch mask comprised of nano pillars, each with a diameter of $33 \mathrm{~nm}$, for nanowire pattern transfer.

The etch processes investigated for nanowire realisation are detailed in Table V. Except for the flow rate of $\mathrm{H}_{2}$ and $\mathrm{O}_{2}$, all other process parameters were kept identical between the etch recipes. From Fig. 13, it is observed that highly vertical nanowires are realised with all three etch conditions, with sidewall-to-substrate angles in the range of $80-82^{\circ}$ and nanowire heights in the range of $45-50 \mathrm{~nm}$. A trend of improving sidewall verticality with increases in $\mathrm{H}_{2}$ and $\mathrm{O}_{2}$ flow rate is noted, albeit the improvements are only marginal.

TABLE V. Summary of ICP etch conditions, based around a $\mathrm{Cl}_{2} / \mathrm{CH}_{4} / \mathrm{H}_{2} / \mathrm{O}_{2}$ chemistry, investigated for nanowire etching.

\begin{tabular}{lccccccc}
\hline Sample & $\begin{array}{c}\text { Etch } \\
\text { Chemistry }\end{array}$ & $\begin{array}{c}\text { Flow rate } \\
(\mathbf{s c c m})\end{array}$ & $\begin{array}{c}\text { Coil/Platen } \\
\text { Power } \\
(\mathbf{W})\end{array}$ & $\begin{array}{c}\text { Pressure } \\
(\text { mTorr })\end{array}$ & $\begin{array}{c}\text { Bias } \\
(\text { V) }\end{array}$ & $\begin{array}{c}\text { Temperature } \\
\text { (C) }\end{array}$ & $\begin{array}{c}\text { Duration } \\
\text { (min) }\end{array}$ \\
\hline $\mathrm{NW}-\mathrm{A}$ & $\mathrm{Cl}_{2} / \mathrm{CH}_{4} / \mathrm{H}_{2} / \mathrm{O}_{2}$ & $6 / 10 / 15 / 0.5$ & $250 / 50$ & 2 & 113 & 120 & 2.5 \\
$\mathrm{NW}-\mathrm{B}$ & $\mathrm{Cl}_{2} / \mathrm{CH}_{4} / \mathrm{H}_{2} / \mathrm{O}_{2}$ & $6 / 10 / 22 / 0.5$ & $250 / 50$ & 2 & 113 & 120 & 2.5 \\
$\mathrm{NW}-\mathrm{C}$ & $\mathrm{Cl}_{2} / \mathrm{CH}_{4} / \mathrm{H}_{2} / \mathrm{O}_{2}$ & $6 / 10 / 22 / 1$ & $250 / 50$ & 2 & 113 & 120 & 2.5 \\
\hline
\end{tabular}
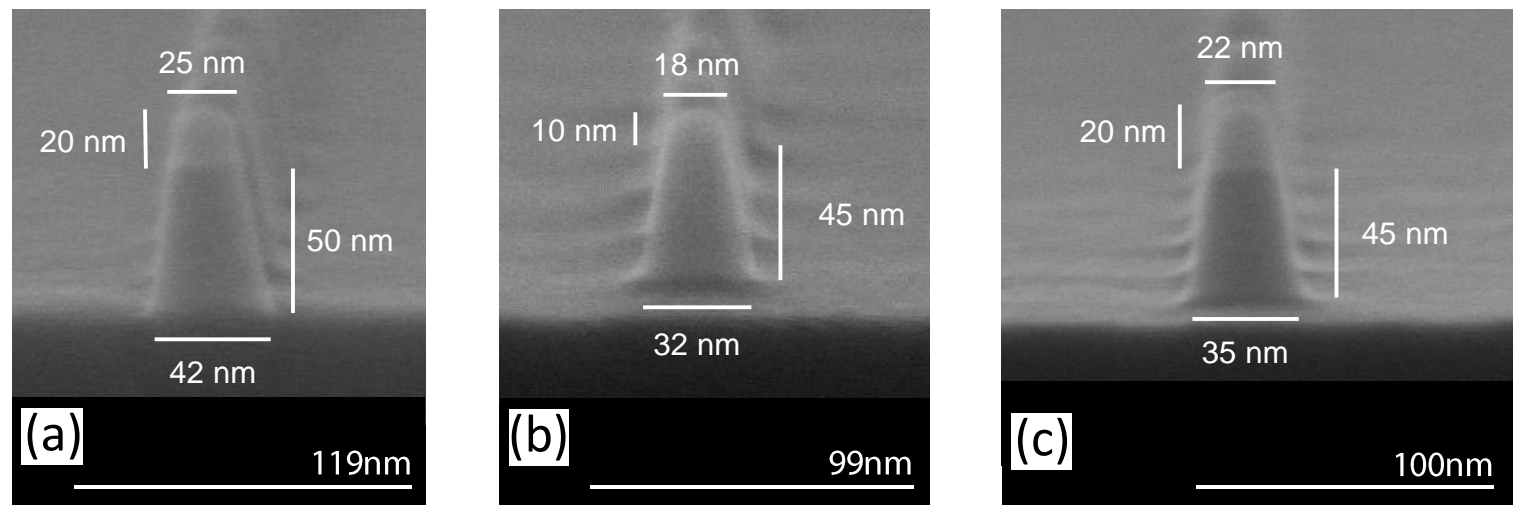

Figure 13. SEM of nanowires etched in $\mathrm{In}_{0.53} \mathrm{Ga} 0.47 \mathrm{As}$ using a $\mathrm{Cl}_{2} / \mathrm{CH}_{4} / \mathrm{H}_{2} / \mathrm{O}_{2}$ chemistry, for the ICP process conditions of (a) NW-A, (b) NW-B and (c) NW-C listed in Table V. 
$\underline{\text { Post-etch Sidewall Passivation Schemes }}$

Hydrogenation. The preparation of clean, well-ordered, stoichiometric and atomically smooth surfaces are of importance in semiconductor processing. Atomic hydrogen has been demonstrated to be an effective surface preparation technique due to its ability to remove carbon-containing contaminants and native oxides (36-38). The lower temperatures required of atomic hydrogen cleaning alleviates the problems of group $\mathrm{V}$ desorption and surface roughening typically associated with high temperature thermal cleaning of substrates prior to epitaxial growth (36-38). A notable obstacle in III-V MOS technology is the presence of a large density of defects at the dielectric/semiconductor interface. This can result in the Fermi level to be pinned, thereby limiting logic performance. Native oxides present on III-V surfaces have been proposed as one cause of Fermi level pinning (39). The reduction and/or removal of these oxides by means of atomic hydrogen cleaning have been shown to unpin the Fermi level $(40,41)$ and reduce interface defect density (42). Another key feature of atomic hydrogen is its ability to passivate native defects within the semiconductor $(23,30,43)$. This attribute has also been exploited in $\mathrm{GaN}$ and GaAs to recover damage arising from dry etch processing through the passivation of etch-induced defects $(44,45)$. This motivates an investigation of atomic hydrogen as a postetch treatment for the alleviation of etch-induced damage in $\operatorname{In}_{0.53} \mathrm{Ga}_{0.47} \mathrm{As}$.

Atomic hydrogen is often introduced into semiconductors through controlled methods such as direct implantation (43), exposure to hydrogen plasmas $(36,38,42-44)$ and from thermal cracking of molecular hydrogen $(36-38,40,41)$. The first two methods, though, carry the risk of physical and electronic damage to the near surface regions of the semiconductor due to the presence of energetic ions $(36,43)$. Here, we employ a photonassisted hydrogenation process (46) developed by Amethyst Research Incorporated to investigate mitigation of damage induced by the fin etch process. This process involves the irradiation of samples with an ultraviolet (UV) light source in a hydrogen ambient. The extent of hydrogen incorporation is controlled and optimized by temperature, exposure time and pressure.

To investigate the effects of hydrogenation, four MOSCAPs were fabricated on samples of (100) oriented $\mathrm{In}_{0.53} \mathrm{Ga}_{0.47} \mathrm{As}, 1 \mu \mathrm{m}$ thick, $\mathrm{n}$-doped $4 \times 10^{17} \mathrm{~cm}^{-3}$ using the process flow of Fig. 6. For a controlled study, one sample did not see any etch process prior to MOSCAP fabrication. The remaining three samples were subject to a fin etch process. The process details are $\mathrm{Cl}_{2} / \mathrm{CH}_{4} / \mathrm{H}_{2}: 6 / 10 / 15 \mathrm{sccm}$, coil/platen powers of $500 / 75 \mathrm{~W}, 2 \mathrm{mT}$ Torr, $182 \mathrm{~V}, 60^{\circ} \mathrm{C}, 60 \mathrm{~s}$. A MOSCAP was directly fabricated on one of the etched samples. The remaining two samples underwent hydrogenation at different stages of the process flow for MOSCAP fabrication shown in Fig. 6. One sample underwent hydrogenation after the etch (post-etch hydrogenation) while the other was hydrogenated after $\mathrm{Al}_{2} \mathrm{O}_{3}$ deposition (post ALD high-k hydrogenation). Hydrogenation was carried out at a temperature of $325^{\circ} \mathrm{C}$ for $30 \mathrm{~min}$, with the pressure set at $1 \mathrm{mbar}$.

Multi-frequency $(100 \mathrm{~Hz}$ to $1 \mathrm{MHz}) \mathrm{C}-\mathrm{V}$ characteristics acquired at room temperature from the four samples are shown in Fig. 14. The electrical metrics extracted from the C-V curves of each sample are also detailed in Table VI. Although the post-etch hydrogenated sample shows an improvement across all metrics from the etched sample, the obtained 
enhancement is marginal. In contrast, a significant reduction in stretch-out and depletion dispersion is obtained for the post high-k hydrogenated sample. These results suggest that hydrogenation done post high-k is more effective in alleviating etch-induced damage. The large conductance peak associated with the etched samples at a constant frequency of $1 \mathrm{MHz}$ shown in Fig. 15 is reduced substantially in magnitude after post-etch hydrogenation. A larger reduction in the peak value is obtained by hydrogenating the etched sample post high-k as opposed to post-etch.
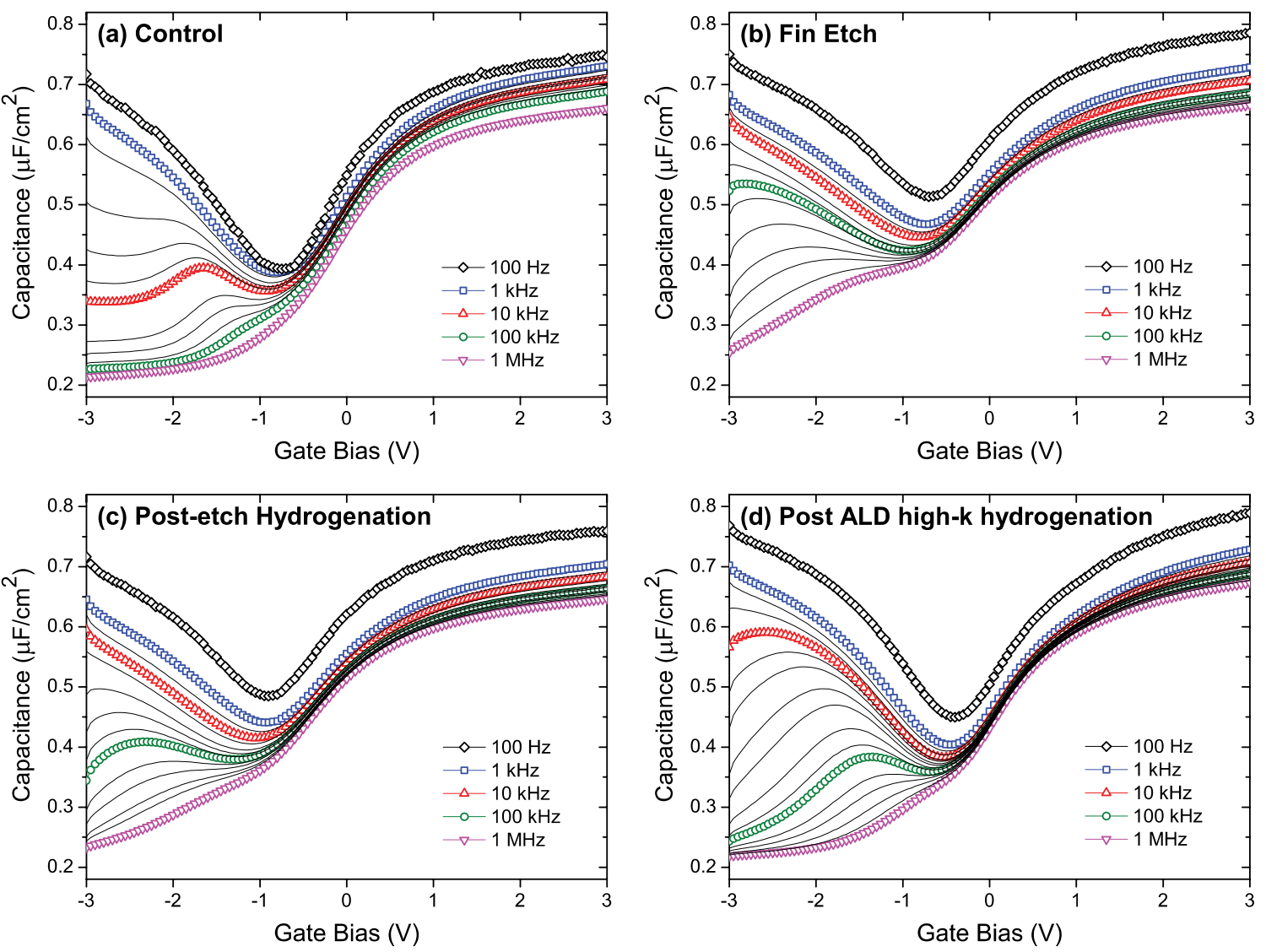

Figure 14. Multi-frequency, room temperature $\mathrm{C}-\mathrm{V}$ characteristics of $\mathrm{Au} / \mathrm{Pt} / \mathrm{Al}_{2} \mathrm{O}_{3} / \mathrm{n}$ $\mathrm{In}_{0.53} \mathrm{Ga}_{0.47}$ As MOSCAPs with the InGaAs sample (a) unetched (control), (b) only etched, etched and subjected to the treatments of (c) post-etch hydrogenation and (d) post ALD high-k hydrogenation.

TABLE VI. Summary of metrics derived from the C-V responses of samples investigated in the hydrogenation experiment.

\begin{tabular}{lccc}
\hline Sample & $\begin{array}{c}\Delta \mathbf{C}_{\text {acc }} \\
(\boldsymbol{\%} / \mathbf{d e c})\end{array}$ & $\begin{array}{c}\mathbf{d C / d V ~} \mathbf{~ 1 0} \mathbf{~ 1 0}^{-7} \\
\left(\mathbf{F} / \mathbf{c m}^{2} \mathbf{. V}\right)\end{array}$ & $\begin{array}{c}\Delta \mathbf{m V} \\
(\mathbf{m V})\end{array}$ \\
\hline Control & 2.84 & 2.49 & 322 \\
Fin etch & $3.82(+34.5 \%)$ & $1.63(-34.5 \%)$ & $605(+87.9 \%)$ \\
Post-etch hydrogenation & $3.72(+31.0 \%)$ & $1.81(-27.3 \%)$ & $595(+84.8 \%)$ \\
Post ALD high-k hydrogenation & $3.68(+29.6 \%)$ & $2.31(-7.2 \%)$ & $334(+3.7 \%)$ \\
\hline
\end{tabular}




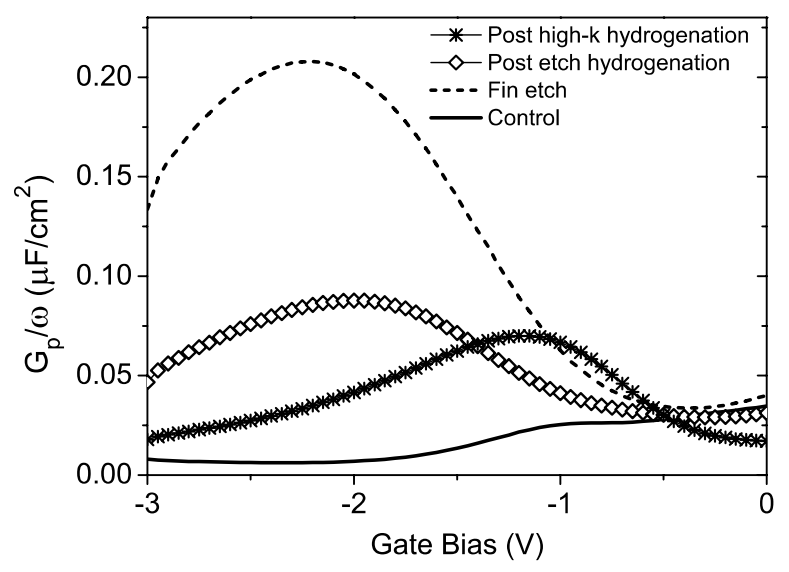

Figure $15 . \mathrm{G}_{\mathrm{p}} / \omega$ versus $\mathrm{V}_{\mathrm{g}}$ of $\mathrm{Au} / \mathrm{Pt} / \mathrm{Al}_{2} \mathrm{O}_{3} / \mathrm{n}-\mathrm{In}_{0.53} \mathrm{Ga}_{0.47} \mathrm{As}$ MOSCAPs investigated in the hydrogenation experiment, at a constant frequency of $1 \mathrm{MHz}$.

Digital Etch In standard wet etching, semiconductors are immersed into a solution comprising an oxidising agent and an etching agent. Etching proceeds through the simultaneous process of surface oxidation and oxide etching. As a result, the depth of material etched is dictated by the length of time the semiconductor is exposed to the etchant. Digital etch, on the other hand, separates the two processes of oxidation and oxide removal. Etching is then achieved through the sequential application of the oxidant and etchant to ensure the chemical reactions associated with each process are independent of each other. $(47,48)$ Due to the self-limiting nature of the oxidation process, the depth of material removed is only dependent on the number of etch cycles and not on the etch time (48). The main benefit of digital etch compared to standard wet etching is the fact that etching can be performed in a controlled manner. This property of digital etch can be exploited in two ways, the first being for the removal of dry etch damaged semiconductor layers (27). Digital etch also offers a route for ultimate fin/nanowire scaling (49).

In this work, we assess the impact of a digital etch clean for the mitigation of damage induced by fin etch processing. This is investigated on a sample of (100) oriented $\mathrm{In}_{0.53} \mathrm{Ga}_{0.47} \mathrm{As}, 1 \mu \mathrm{m}$ thick, n-doped $4 \times 10^{17} \mathrm{~cm}^{-3}$ blanket etched using the $120^{\circ} \mathrm{C}$, $\mathrm{Cl}_{2} / \mathrm{CH}_{4} / \mathrm{H}_{2} / \mathrm{O}_{2}$ etch process. The details of the etch are $\mathrm{Cl}_{2} / \mathrm{CH}_{4} / \mathrm{H}_{2} / \mathrm{O}_{2}: 6 / 10 / 15 / 0.5 \mathrm{sccm}$, coil/platen powers of $200 / 25 \mathrm{~W}, 2 \mathrm{mT}$ orr, $113 \mathrm{~V}, 120^{\circ} \mathrm{C}, 5 \mathrm{~min}$. The etched surface is then subjected to three cycles of the digital etch clean. Each cycle is a two-step process comprising a self-limiting $\mathrm{O}_{2}$ plasma oxidation in a $\mathrm{RIE}$ tool followed by a 10 s rinse in diluted $\mathrm{H}_{2} \mathrm{SO}_{4}$ for oxide removal. Plasma oxidation was carried out under the conditions of $50 \mathrm{sccm}, 50 \mathrm{mTorr}, 52 \mathrm{~V}, 22^{\circ} \mathrm{C}, 3 \mathrm{~s}$. We estimate that one cleaning cycle etches $1 \mathrm{~nm}$ of the $\mathrm{In}_{0.53} \mathrm{Ga}_{0.47} \mathrm{As}$ material. The process flow of Fig. 6 is adopted for the realisation of MOSCAPs on this sample.

The C-V data acquired on the cleaned sample is shown in Fig. 16(a). To elucidate the impact of the digital etch clean, a comparison in $\mathrm{C}-\mathrm{V}$ characteristics is drawn between the cleaned sample, a control sample (Fig. 11(a)) and a sample blanket etched under the same fin etch conditions (Fig. 11(c)). From this comparison, it is evident that the C-V characteristics of the cleaned sample is significantly improved, with all electrical metrics 
showing improvements, over the etched sample. Additionally, the conductance peak of the etched sample is reduced by a factor of three in value after being subjected to the digital etch clean. This highlights the benefit of the digital etch clean for mitigating damage induced by fin etch processes. It is also noteworthy that the $\mathrm{C}-\mathrm{V}$ data between the control sample and the cleaned sample is comparable. This is an important observation as it suggests the etch-induced damage has been completely recovered via the digital etch clean, resulting in the restoration of the $\mathrm{Al}_{2} \mathrm{O}_{3} / \mathrm{In}_{0.53} \mathrm{Ga}_{0.47} \mathrm{As}$ interface to its original state prior to etching. This also implies the damage induced by $120^{\circ} \mathrm{C}, \mathrm{Cl}_{2} / \mathrm{CH}_{4} / \mathrm{H}_{2} / \mathrm{O}_{2}$ etch process only extends to the near surface region, up to a depth of about $3 \mathrm{~nm}$ from the surface based on the etch rate $(1 \mathrm{~nm} /$ cycle $)$ and the number of cleaning cycles used.
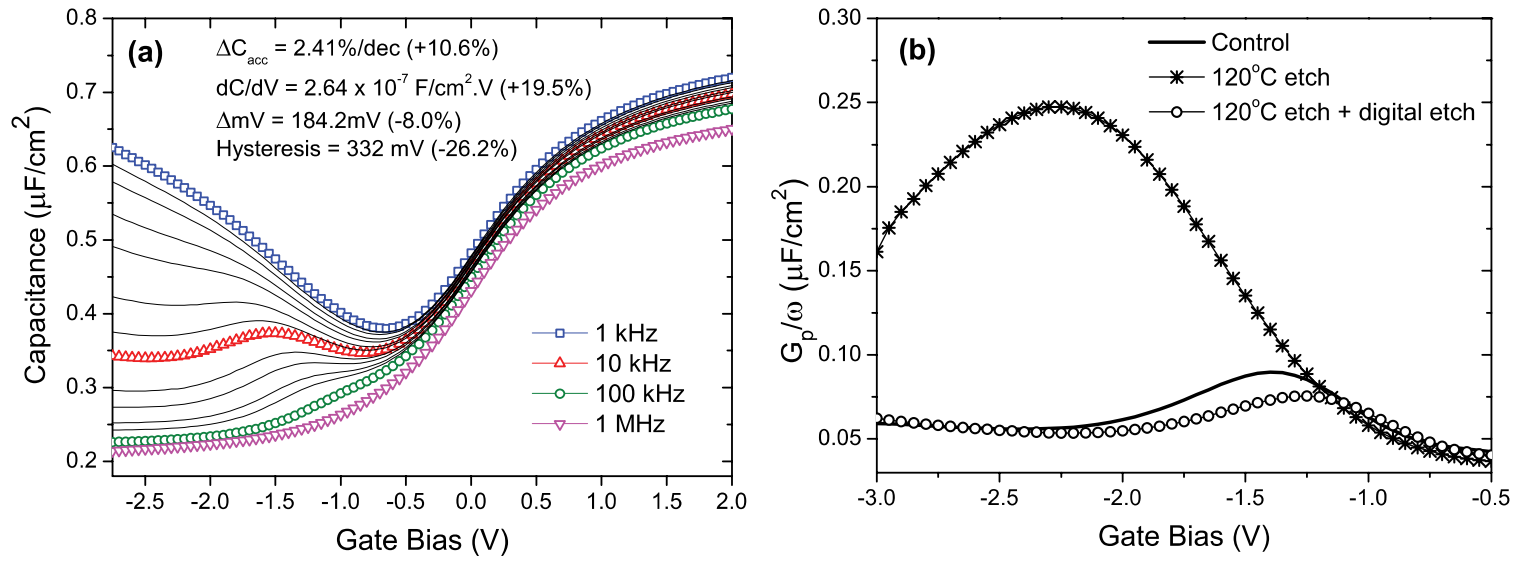

Figure 16. (a) Multi-frequency, room temperature $\mathrm{C}-\mathrm{V}$ characteristics of a $\mathrm{Au} / \mathrm{Pt} / \mathrm{Al}_{2} \mathrm{O}_{3} / \mathrm{n}$ $\mathrm{In}_{0.53} \mathrm{Ga}_{0.47} \mathrm{As}$ MOSCAP with the InGaAs sample subjected to the $120^{\circ} \mathrm{C}, \mathrm{Cl}_{2} / \mathrm{CH}_{4} / \mathrm{H}_{2} / \mathrm{O}_{2}$ based fin etch process followed by the digital etch clean and (b) $G_{p} / \omega$ versus $V_{g}$ of $\mathrm{Au} / \mathrm{Pt} / \mathrm{Al}_{2} \mathrm{O}_{3} / \mathrm{n}-\mathrm{In}_{0.53} \mathrm{Ga}_{0.47} \mathrm{As}$ MOSCAPs with the InGaAs sample subjected to no etch (control), the fin etch process only and the fin etch process followed by the digital etch clean, at a constant frequency of $100 \mathrm{kHz}$.

Mitigation of fin etch damage by means of the digital etch clean was also examined on etched (110) oriented $\operatorname{In}_{0.53} \mathrm{Ga}_{0.47} \mathrm{As}$. For this investigation, 200nm thick n-type (110) $\mathrm{In}_{0.53} \mathrm{Ga}_{0.47}$ As layer doped at $4 \times 10^{17} \mathrm{~cm}^{-3}$ was grown by molecular beam epitaxy (MBE) on (110) $\mathrm{n}+-\mathrm{InP}$ substrate. Of the three samples fabricated from (110) $\mathrm{In}_{0.53} \mathrm{Ga}_{0.47} \mathrm{As}$ for electrical evaluation, one served as control (unetched) while the others were blanket etched. The digital etch clean was then carried out on one of the etched samples. The conditions of the fin etch process, used for blanket etching, and the digital etch clean are identical to that used in the earlier study reporting on the effectiveness of digital etch clean on etched (100) $\mathrm{In}_{0.53} \mathrm{Ga}_{0.47} \mathrm{As}$. The fabrication of MOSCAPs was based on the process flow of Fig. 6 .

The room temperature CV data of the unetched sample (control), the sample subjected to the fin etch process (etched), and for the sample subjected to the fin etch process followed by the digital etch clean (cleaned) are compared in Fig. 17. It is clear that etched sample has significantly degraded $\mathrm{C}-\mathrm{V}$ response, evidenced by a stretch-out in the characteristics and the fact that the $100 \mathrm{kHz}$ and $1 \mathrm{MHz}$ capacitance does not reach the theoretical minimum capacitance of $2.5 \times 10^{-7} \mathrm{~F} / \mathrm{cm}^{2}$. In contrast, the cleaned sample appears to have regained many of the characteristics of the control sample, and indeed the 
peak in depletion around $-1 \mathrm{~V}$, evident in both the $10 \mathrm{kHz}$ and $100 \mathrm{kHz}$ data, is suppressed in the cleaned sample. This implies recovery of damage in etched (110) $\operatorname{In}_{0.53} \mathrm{Ga}_{0.47} \mathrm{As}$, similar to the finding noted for post-etch cleaned (100) $\mathrm{In}_{0.53} \mathrm{Ga}_{0.47} \mathrm{As}$.
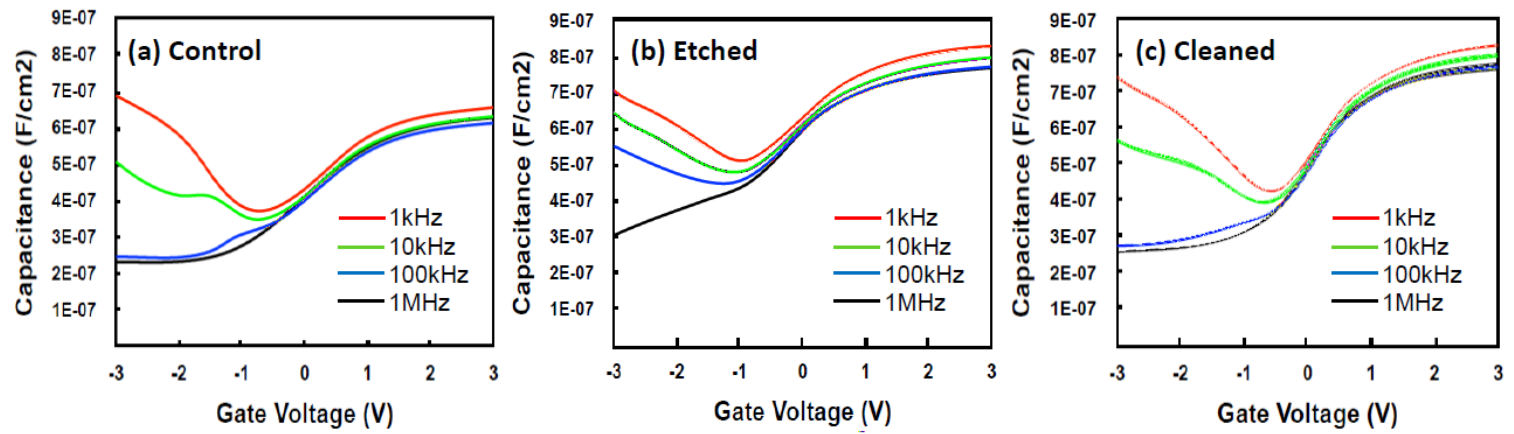

Figure 17. Multi-frequency, room temperature $\mathrm{C}-\mathrm{V}$ characteristics of a $\mathrm{Au} / \mathrm{Pt} / \mathrm{Al}_{2} \mathrm{O}_{3} / \mathrm{n}$ (110) $\mathrm{In}_{0.53} \mathrm{Ga}_{0.47} \mathrm{As}$ MOSCAP with the InGaAs sample (a) unetched (control), (b) subject to the fin etch process (etched) and (c) subjected to the fin etch process followed by the digital etch clean (cleaned).

\section{Conclusion}

The introduction of III-V channels into CMOS, currently aimed at the $7 \mathrm{~nm}$ technology node, would require top-down patterning of III-V fins. The realisation of fins with a vertical profile and a high quality sidewall MOS interface, however, is a challenging prospect. Reason being, highly anisotropic etching required of vertical fin profiles is more damaging to the sidewall. To tackle the conflict between anisotropy and damage, inherent to dry etch processing, we adopted a two-tier approach to realise vertical $\operatorname{In}_{0.53} \mathrm{Ga}_{0.47} \mathrm{As}$ fins with minimum etch damage. In the first tier, we focussed on developing dry etch processes capable of producing high resolution fins with vertical sidewalls and clean etch surfaces. Fin etching was investigated for a variety of chlorine-based chemistries using either a RIE or an ICP process. A fin profile within $3^{\circ}$ of vertical was obtained with the ICP process based around a $\mathrm{Cl}_{2} / \mathrm{CH}_{4} / \mathrm{H}_{2}$ chemistry. Vertical $10 \mathrm{~nm}$ fins with $16: 1$ aspect ratio, perhaps the highest aspect ratio, smallest critical dimension fins to date in $\operatorname{In}_{0.53} \mathrm{Ga}_{0.47} \mathrm{As}$, was also achieved. The process, however, severely degraded the electrical characteristics of MOSCAPs formed on a (100) $\mathrm{In}_{0.53} \mathrm{Ga}_{0.47} \mathrm{As}$ surface subjected to the etch which indicated substantial etch-induced damage. The aim in the second tier was then to mitigate the damage. The modification of the $\mathrm{Cl}_{2} / \mathrm{CH}_{4} / \mathrm{H}_{2}$ chemistry to include $\mathrm{O}_{2}$ resulted in the substantial reduction of etch-induced damage, due to the lowering of the platen power, without compromising on the fin profile. Two post-etch sidewall passivation schemes were also examined for damage mitigation. The first was a photon-assisted hydrogenation process, applied post-etch or post high-k. The electrical performance of MOSCAPs formed on a (100) $\mathrm{In}_{0.53} \mathrm{Ga}_{0.47} \mathrm{As}$ surface subjected to the $\mathrm{Cl}_{2} / \mathrm{CH}_{4} / \mathrm{H}_{2}$ etch indicated a larger reduction in etch damage for hydrogenation done post high-k. In the second approach, a digital etch clean, comprising of a multi-cycle $\mathrm{O}_{2}$ plasma oxidation then oxide removal in $\mathrm{H}_{2} \mathrm{SO}_{4}$, was investigated as a post-etch treatment. The electrical characteristics of MOSCAPs formed on (100) $\mathrm{In}_{0.53} \mathrm{Ga}_{0.47} \mathrm{As}$ and (110) $\mathrm{In}_{0.53} \mathrm{Ga}_{0.47}$ As surfaces subjected to the $\mathrm{Cl}_{2} / \mathrm{CH}_{4} / \mathrm{H}_{2} / \mathrm{O}_{2}$ etch revealed a complete recovery of etch damage. The demonstration of high resolution $(10 \mathrm{~nm})$, near-vertical $\left(\sim 87^{\circ}\right) \mathrm{In}_{0.53} \mathrm{Ga}_{0.47} \mathrm{As}$ fins and the ability to realise 
damage-free sidewalls are of significance for the realisation of high-performance III-V FinFETs.

\section{Acknowledgments}

The authors acknowledge support from the Semiconductor Research Corporation (Task ID 2188.002) and technical support from the James Watt Nanofabrication Centre (JWNC) University of Glasgow.

\section{References}

1. J. A. del Alamo, Nature, 479, 317 (2011).

2. H. Iwai, Microelectron. Eng., 86, 1520 (2009).

3. H. Riel, L. -E. Wernersson, M. Hong, J. A. del Alamo, MRS Bulletin, 39, 668 (2014).

4. I. Ferain, C. A. Colinge, J. -P. Colinge, Nature, 479, 310 (2011).

5. C. C. Wu, D. W. Lin, A. Keshavarzi, C. H. Huang, C. T. Chan, C. H. Tseng, C. L. Chen, C. Y. Hsieh, K. Y. Wong, M. L. Cheng, T. H. Li, Y. C. Lin, L. Y. Yang, C. P. Lin, C. S. Hou, H. C. Lin, J. L. Yang, K. F. Yu, M. J. Chen, T. H. Hsieh, Y. C. Peng, C. H. Chou, C. J. Lee, C. W. Huang, C. Y. Lu, F. K. Yang, H. K. Chen, L. W. Weng, P. C. Yen, S. H. Wang, S. W. Chang, S.W. Chuang, T. C. Gan, T. L. Wu, T. Y. Lee, W. S. Huang, Y. J. Huang, Y. W. Tseng, C. M. Wu, E. Ou-Yang, K. Y. Hsu, L. T. Lin, S. B. Wang, T. M. Kwok, C. C. Su, C. H. Tsai, M. J. Huang, H. M. Lin, A. S. Chang, S. H. Liao, L. S. Chen, J. H. Chen, P. S. Lim, X. F. Yu, S. Y. Ku, Y. B. Lee, P. C. Hsieh, P. W. Wang, Y. H. Chiu, S. S. Lin, H. J. Tao, M. Cao, Y. J. Mii, IEEE IEDM Tech. Dig., 2711 (2010).

6. S. Oktyabrsky, M. Yakimov, V. Tokranov, R. Kambhampati, H,. Bakhru, S. Koveshnikov, W. Tsai, F. Zhu, J. Lee, International Journal of High Speed Electronics and Systems, 18, 761 (2008).

7. P. K. Hurley, E. O'Connor, V. Djara, S. Monaghan, I. M. Povey, R. D. Long, B. Sheehan, J. Lin, P. C. McIntyre, B. Brennan, R. M. Wallace, M. E. Pemble, K. Cherkaoui, IEEE Trans. Device Mater. Rel., 13, 429 (2013).

8. V. Chobpattana, E. Mikheev, J. Y. Zhang, T. E. Mates, S. Stemmer, J. Appl. Phys., 116, 124104 (2014).

9. R. Oxland, S. W. Chang, X. Li, S. W. Wang, G. Radhakrishnan, W. Priyantha, M. J. H. van Dal, C. H. Hsieh, G. Vellianitis, G. Doornbos, K. Bhuwalka, B. Duriez, I. Thayne, R. Droopad, M. Passlack, C. H. Diaz, Y. C. Sun, IEEE Elec. Dev. Lett., 33, 501 (2012).

10. R. J. W. Hill, C. Park, J. Barnett, J. Price, J. Huang, N. Goel, W. -Y. Loh, J. Oh, C. E. Smith, P. Kirsch, P. Majhi, R. Jammy, IEEE IEDM Tech. Dig., 621 (2010).

11. S. Lee, V. Chobpattana, C. -Y. Huang, B. J. Thibeault, W. Mitchell, S. Stemmer, A. C. Gossard, M. J. W. Rodwell, VLSI Technology Tech. Dig., 54 (2014).

12. C. Y. Huang, S. Lee, V. Chobpattana, S. Stemmer, A. C. Gossard, B. Thibeault, W. Mitchell, M. Rodwell, IEEE IEDM Tech. Dig., 586 (2014).

13. S. W. Chang, X. Li, R. Oxland, S. W. Wang, C. H. Wang, R. Contreras-Guerrero, K. K. Bhuwalka, G. Doornbos, T. Vasen, M. C. Holland, G. Vellianitis, M. J. H. van Dal, B. Duriez, M. Edirisooriya, J. S. Rojas-Ramirez, P. Ramvall, S. Thoms, 
U. Peralagu, C. H. Hsieh, Y. S. Chang, K. M. Yin, E. Lind, L. -E. Wernersson, R. Droopad, I. Thayne, M. Passlack, C. H. Diaz, IEEE IEDM Tech. Dig., 417 (2013).

14. S. J. Pearton, U. K. Chakrabarti, W. S. Hobson and A. P. Perley, J. Electrochern. Soc., 137, 3188 (1990).

15. J. W. Lee, E. S. Lambers, C. R. Abernathy, S. J. Pearton, R. J. Shul, F. Ren, W. S. Hobson, C. Constantine, Mater. Sci. Semicond. Process., 1, 65 (1998).

16. T Maeda, J. W. Lee, R. J. Shul, J. Han, J. Hong, E. S. Lambers, S. J. Pearton, C. R. Abernathy, W. S. Hobson, Appl. Surf. Sci., 143, 174 (1999).

17. T Maeda, J. W. Lee, R. J. Shul, J. Han, J. Hong, E. S. Lambers, S. J. Pearton, C. R. Abernathy, W. S. Hobson, Appl. Surf. Sci., 143, 183 (1999).

18. S. J. Pearton, F. Ren, T. R. Fullowan, A. Katz, W. S. Hobson, U. K. Chakrabarti, C. R. Abernathy, Mater. Chem. Phys, 32, 215 (1992).

19. C. D. Wilkinson and M. Rahman, Philos Trans A Math Phys Eng Sci., 362, 125 (2004).

20. F. Karouta, J. Phys. D: Appl. Phys., 47, 233501 (2014).

21. S. J. Fonash, J. Electrochem. Soc., 137, 3885 (1990).

22. G. Franz, J. Vac. Sci. Technol. A, 19, 762 (2001).

23. T. R. Hayes, W. C. Dautremont-Smith, H. J. Luftman, J. W. Lee, Appl. Phys. Lett., 55, 56 (1989).

24. R. van Roijen, M. B. M. Kemp, C. W. Bulle-Lieuwma, L. J. van Ijzerdoorn, T. L. Thijssen, J. Appl. Phys., 70, 3983 (1991).

25. S. J. Pearton, U. K. Chakrabarti, F. A. Baiochi, Appl. Phys. Lett., 55,1633 (1989).

26. A. Dixit, T. B. Hook, J. B. Johnson, E. J. Nowak and K. V. Murali, in Physics of Semiconductor Devices, V. K. Jain and A. Verma, Editors, p. 5, Springer-Verlag, New York (2014).

27. X. Zhao, J. A. del Alamo, IEEE Elec. Dev. Lett., 35, 521 (2014).

28. M. Volatier, D. Duchesne, R. Morandotti, R. Arès, V. Aimez, Nanotechnology, 21, 134014 (2010).

29. L. Gatilova, S. Bouchoule, S. Guilet, P. Chabert, J. Vac. Sci. Technol. A, 27, 262 (2009).

30. L. Goubert, R. L. Van Meirhaeghe, P. Clauws, F. Cardon, P. Van Daele, J. Appl. Phys., 82, 1696 (1997).

31. H. C. Neitzert, R. Fang, M. Kunst, N. Layadi, J. Vac. Sci. Technol. B, 18, 2803 (2000).

32. T. R. Hayes, U. K. Chakrabarti, F. A. Baiocchi, A. B. Emerson, H. S. Luftman, W. C. Dautremon-Smith, J. Appl. Phys., 68, 785 (1990).

33. A. R. Long, M. Rahman, I. K. MacDonald, M. Kinsler, S. P. Beaumont, C. D. W. Wilkinson, C. R. Stanley, Semicond. Sci. Technol., 8, 39 (1993).

34. U. Peralagu, I. M. Povey, P. Carolan, J. Lin, R. Contreras-Guerrero, R. Droopad, P. K. Hurley and I. G. Thayne, Appl. Phys. Lett., 105, 162907 (2014).

35. E. O'Connor, B. Brennan, V. Djara, K. Cherkaoui, S. Monaghan, S. B. Newcomb, R. Contreras, M. Milojevic, G. Hughes, M. E. Pemble, R. M. Wallace, and P. K. Hurley, J. of Appl. Phys., 109, 024101 (2011).

36. G. R. Bell, N. S. Kaijaks, R. J. Dixon, C. F. McConville, Surf. Sci., 401, 125 (1998).

37. A. Khatiri, J. M. Ripalda, T. J. Krzyzewski, G. R. Bell, C. F. McConville, T. S. Jones, Surf. Sci., 548, L1 (2004).

38. T. Kikawa, I. Ochiai, S. Takatani, Surf. Sci., 316, 238 (1994).

39. H. Hasegawa, M. Akazawa, A. Domanowska, B. Adamowicz, Appl. Surf. Sci., 256, 5698 (2010). 
40. W. Melitz, J. Shen, T. Kent, A. C. Kummel and R. Droopad, J. Appl. Phys., 110, 013713 (2011).

41. J. Szuber, Vacuum, 55, 209 (2000).

42. A. D. Carter, W. J. Mitchell, B. J. Thibeault, J. J. M. Law, M. J. W. Rodwell, Appl. Phys. Express, 4, 091102 (2011).

43. S. J. Pearton, J. W. Corbett, T. S. Shi, Appl. Phys. A, 43, 153 (1987).

44. B. -S. Yoo, S. -J. Park, K. -H. Park, J. Vac. Sci. Technol. A, 13, 931 (1995).

45. S. Chen, Y. Lu, R. Kometani, K. Ishikawa, H. Kondo, Y. Tokuda, M. Sekine, M. Hori, AIP Advances, 2, 022149 (2012).

46. H1. T. D. Golding and R. P. Hellmer 2008, Photon-assisted hydrogenation process, US Patent 0268658.

47. X. Cao, I. Thayne, Microelectron. Eng., 67, 333 (2003).

48. G. C. DeSalvo, C. A. Bozada, J. L. Ebel, D. C. Look, J. P. Barrette, C. L. A. Cerny, R. W. Dettmer, J. K. Gillespie, C. K. Havasy, T. J. Jenkins, K. Nakano, C. I. Pettiford, T. K. Quach, J. S. Sewell, G. David Via, J. Electrochem. Soc., 143, 3652 (1996).

49. J. Lin, X. Zhao, D. A. Antoniadis, J. A. del Alamo, IEEE Elec. Dev. Lett., 35, 440 (2014). 